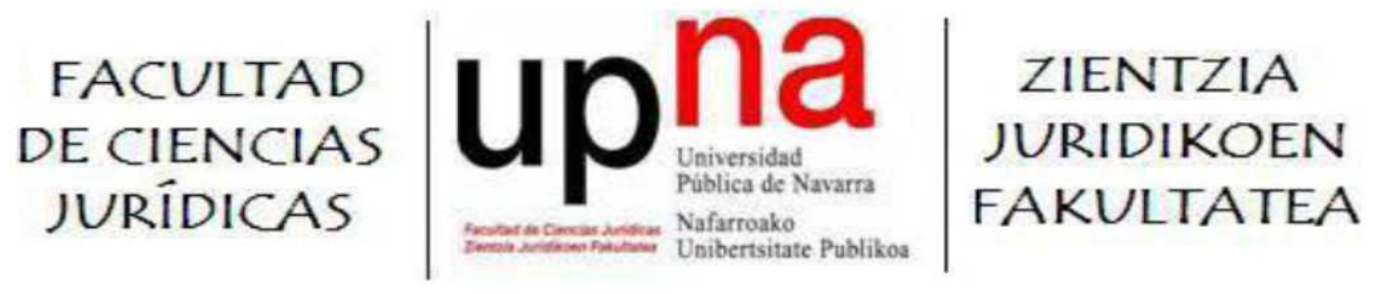

TRABAJO FIN DE GRADO

\title{
MEDIDAS CONTRA LA CORRUPCIÓN \\ EN LA CONTRATACIÓN PÚBLICA
}

\author{
Luis Ibarrola Berasain
}

\section{DIRECTOR}

José Francisco Alenza García

Pamplona,

12 de enero de 2016 
Real Decreto de 27 de febrero de 1852, de Bravo Murillo:

"Señora [Reina Isabel II]:

Autorizado competentemente por V.M., previo acuerdo del Consejo de Ministros, presentó el de Haciendo a las Cortes en 29 de diciembre de 1850 un proyecto de ley de contratos sobre servicios públicos, con el fin de establecer ciertas trabas saludables, evitando los abusos fáciles de cometer en una materia de peligrosos estímulos, y de garantizar la Administración contra los tiros de la maledicencia” 


\section{RESUMEN:}

Uno de los ámbitos en los que se dan actos de corrupción con mayor frecuencia es el de la contratación pública, la cual supone en España alrededor del 11\% del PIB nacional anual. Por ello, y porque la corrupción ataca de raíz el fundamento de un Estado democrático y de derecho, el destino ilícito de fondos públicos es especialmente grave. El presente trabajo trata diferentes mecanismos jurídicos dirigidos a limitar la proliferación de actos de corrupción. Para ello se ofrece una definición jurídica de corrupción y se describe la regulación de la contratación pública. En segundo lugar, se realiza un análisis de los principios que rigen la contratación pública cuya finalidad sea evitar que surjan situaciones de conflictos de intereses públicos y privados. Finalmente, se examinan de manera profusa varios mecanismos contra la corrupción, estableciendo la fase de adjudicación como eje de los mismos.

Palabras Clave: Corrupción, Contratación Pública, ley de Contratos del Sector Público, Objetividad, Transparencia.

\section{ABSTRACT:}

Public procurement is one of the areas where corruption is most frequent, whereas accounts for $11 \%$ of Spanish annual GDP. Therefore, and because corruption attacks by the root the bases of democratic rule of law, unlawful allocations of public funds are particularly serious. This paper deals with different legal mechanisms to limit the proliferation of corruption. It offers a legal definition of corruption and an examination of public procurement regulation. Secondly, it analyses the principles governing public procurement which aim to prevent the emergence of conflicts between public and private interests. Finally, several mechanisms against corruption are profusely discussed, establishing the award phase as a fundamental point.

KEY WORDS: Corruption, Public Procurement, Public Sector Contracts Act, OBJECTIVITY, TRANSPARENCY. 


\section{ÍNDICE GENERAL:}

Abreviaturas 6

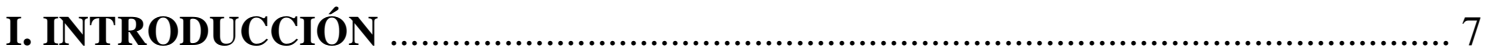

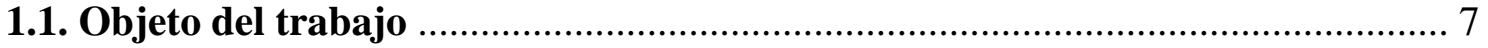

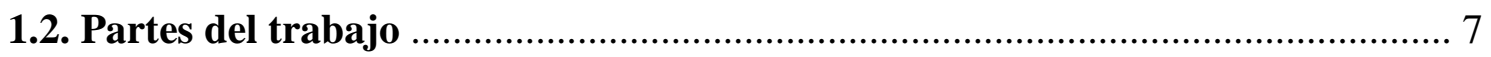

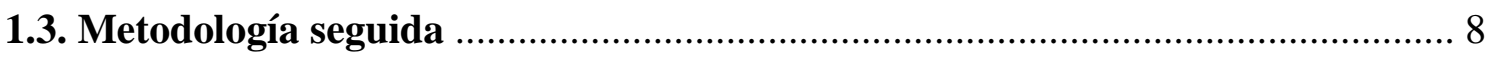

II. CORRUPCIÓN EN LA CONTRATACIÓN PÚBLICA ESPAÑOLA ................ 8

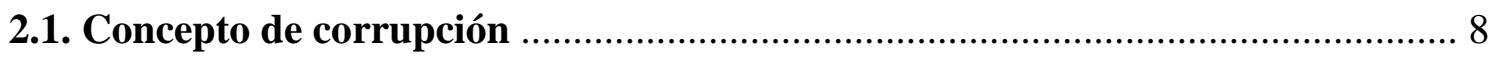

2.2. Dimensión y alcance del problema de la corrupción en España ...................... 11

2.3. Situación de la regulación de la contratación pública en España .................... 13

2.3.1. Evolución y características de la normativa vigente .............................. 13

2.3.2. Directivas pendientes de trasposición y Anteproyecto de LCSP ............. 15

III. PRINCIPIOS DE LA CONTRATACIÓN PÚBLICA …................................ 18

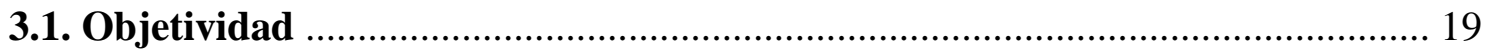

3.2. Igualdad de acceso a licitaciones y no discriminación .................................. 21

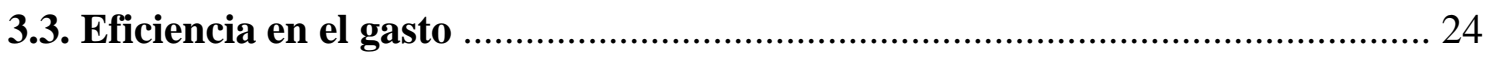

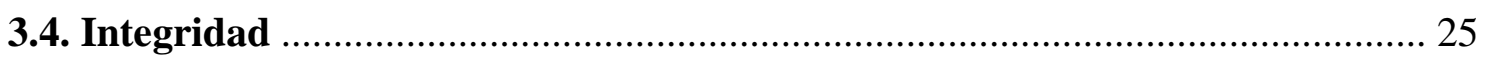

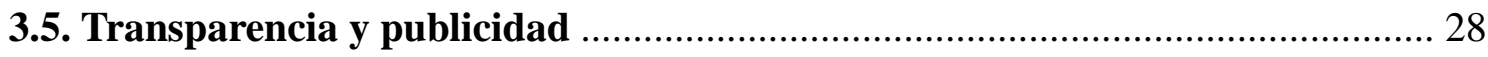

IV. MEDIDAS CONTRA LA CORRUPCIÓN …................................................ 31

4.1. Medidas previas a la adjudicación del contrato …......................................... 31

4.1.1. Publicación de información .................................................................... 32

a) Difusión de información .................................................................. 32

b) La publicidad de los contratos menores ........................................ 34

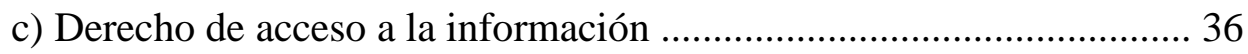


4.1.2. Profesionalización y neutralidad de la Mesa de contratación 37

4.1.3. Limitación del ius variandi ........................................................................ 39

4.1.4. Colusión empresarial en el proceso de licitación ..................................... 42

4.2. Medidas posteriores a la adjudicación del contrato ...................................... 44

4.2.1. Rendición de cuentas .............................................................................. 44

a) Plataforma de contratación del sector público .................................. 44

b) Portal de la transparencia .................................................................. 45

4.2.2. Recuperación de los bienes defraudados .................................................. 46

4.2.3. Organismos de control y fiscalización ................................................... 47

a) Tribunal de Cuentas ........................................................................4

b) Inspecciones Generales de Servicios ...............................................48

c) Oficina de Conflictos de Intereses ......................................................49

d) Consejo de Transparencia y Buen Gobierno ................................... 49

e) Junta Consultiva de Contratación Administrativa ...............................50

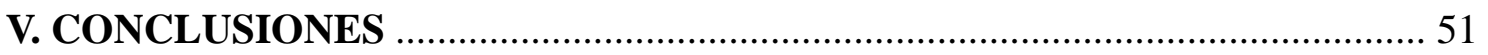

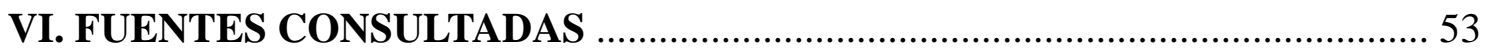

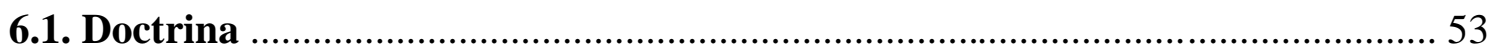

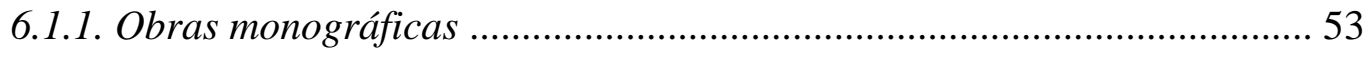

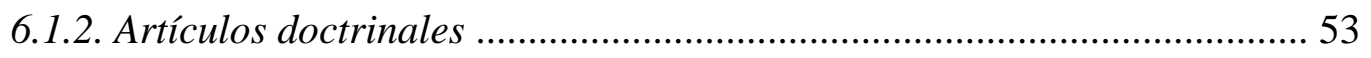

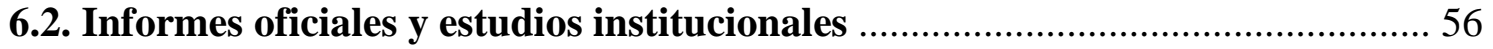

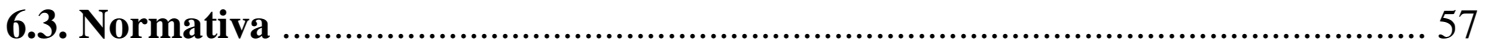

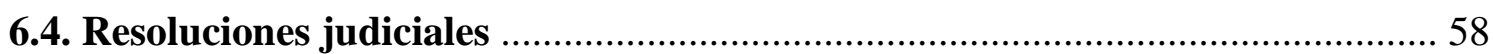




\section{ABREVIATURAS}

Art./Arts.

BOE

$\mathrm{CC}$

$\mathrm{CE}$

CEE

CIS

CNMC

EBEP

Artículo/s.

Boletín Oficial del Estado.

Código Civil.

Constitución Española.

Comunidad Económica Europea.

Centro de Investigaciones Sociológicas.

Comisión Nacional de los Mercados y la Competencia.

Ley 7/2007, de 12 de abril, del Estatuto Básico del Empleado Público.

Estatuto del alto cargo Ley 3/2015, de 30 de marzo, reguladora del ejercicio del Alto Cargo de la Administración General del Estado.

FMI

Fondo Monetario Internacional.

JCCA

Junta Consultiva de Contratación Administrativa.

LECrim

Real Decreto de 14 de septiembre de 1882 por el que se aprueba la Ley de Enjuiciamiento Criminal.

LOTCu Ley Orgánica 2/1982, de 12 de mayo, del Tribunal de Cuentas.

LRJPAC Ley 30/1992, de 26 de noviembre, de Régimen Jurídico de las Administraciones Públicas y del Procedimiento Administrativo Común.

LTAIBG

Ley 19/2013, de 9 de diciembre, de Transparencia, Acceso a la Información pública y Buen Gobierno.

Núm.

Número.

OCDE

ORGA

Organización para la Cooperación y el Desarrollo Económico.

Pág./Págs.

Oficina de Recuperación y Gestión de Activos.

PIB

Página/s.

Producto Interior Bruto.

SARA

Contratos Sujeto a Regulación Armonizada.

STJCE/STJUE

Sentencia del Tribunal de Justicia de las Comunidades Europeas/Sentencia del Tribunal de Justicia de la Unión Europea.

STS/SSTS

Sentencia/s del Tribunal Supremo.

TACRC

Tribunal Administrativo Central de Recursos Contractuales.

TFUE

TRLCSP

Tratado de Funcionamiento de la Unión Europea.

Real Decreto Legislativo 3/2011, de 14 de noviembre, por el que se aprueba el texto refundido de la Ley de Contratos del Sector Público.

UE

Unión Europea. 


\section{INTRODUCCIÓN}

\subsection{Objeto del trabajo}

La desconfianza institucional presente actualmente en España tiene como una de sus causas los cuantiosos actos de corrupción que se han perpetrado por parte de personas pertenecientes a organismos públicos, siendo la contratación pública uno de los ámbitos donde mayor número y de mayor cuantía se han producido.

Si bien la corrupción en la contratación pública ha sido una cuestión a la que se ha intentado poner coto desde aquel Real Decreto de Bravo Murillo de 1852 en tiempos de Isabel II, la crisis económica que lleva asolando a España desde 2008 ha favorecido el afloramiento a la luz pública de una serie de prácticas corruptas llevadas a cabo en los últimos años.

Consecuencia de ello ha sido la insistencia creciente con la que los ciudadanos demandan de las administraciones públicas más transparencia y una mayor rendición de cuentas de sus actuaciones públicas. Asimismo, se les exige más información sobre los intereses privados que tienen en juego los funcionarios y cargos públicos y su vinculación con la toma de decisiones de las administraciones. Todo ello para poder recuperar la confianza en que la administración actúa siguiendo los valores democráticos del ordenamiento satisfaciendo el interés general.

El objeto de este trabajo es analizar y examinar los diferentes mecanismos con que cuenta el ordenamiento jurídico español para evitar conductas de corrupción en el ámbito de la contratación pública. Se prescinde de aquellos referidos al sistema penal para centrarse en varios relativos al Derecho administrativo que previenen y dificultan la proliferación de actos de corrupción o sirven como elementos de control.

\subsection{Partes del trabajo}

El trabajo se estructura en tres grandes apartados. Primero, se lleva a cabo un análisis de la situación de la corrupción en la contratación pública en España. Se define el concepto jurídico de corrupción que será utilizado a lo largo de todo el trabajo y se hace un breve análisis sobre la incidencia de la misma en España. Asimismo, se hace referencia al encuadre legal de la contratación del sector público para enmarcar la situación y conocer qué legislación es objeto de vulneración mediante los actos de corrupción.

En segundo lugar, se lleva a cabo un análisis de los principios de la contratación 
pública susceptibles de ser conculcados mediante la realización de actos de corrupción pública. En la tercera parte, tras la contextualización del problema, se entra en el núcleo del trabajo, estudiando las diferentes medidas jurídico-administrativas concretas y su eficacia para combatir la existencia de actos de corrupción pública en el ámbito de la contratación.

Finalmente, se señalan las diferentes conclusiones que se han obtenido mediante la realización del presente trabajo y se ofrecen la bibliografía y la jurisprudencia utilizadas.

\subsection{Metodología seguida}

Para el desarrollo del presente documento se han llevado a cabo las siguientes pautas de trabajo. Por una parte, se ha estudiado la legislación relativa a la contratación pública en España, tanto su origen y evolución, como la normativa europea pendiente de trasposición.

Tras esta primera fase de conocimiento de la situación jurídica de la materia objeto de este trabajo, se ha producido una aproximación al tema de la corrupción mediante la lectura de artículos de revistas especializadas, manuales que tratan el asunto de manera específica y páginas web que incluyen artículos e informes públicos acerca de la cuestión tratada.

Finalmente, se ha profundizado en el tema de la corrupción en la contratación pública acudiendo a las fuentes de información primaria de donde se obtenía la información con que se elaboraban los documentos examinados, muy especialmente de la jurisprudencia.

\section{CORRUPCIÓN EN LA CONTRATACIÓN PÚBLICA ESPAÑOLA}

\subsection{Concepto de corrupción}

Es esencial precisar al comienzo del trabajo el concepto que se tiene en cuenta de corrupción a lo largo del mismo. Muchos son los estudios, tanto nacionales ${ }^{1}$ como internacionales ${ }^{2}$, que desde finales del siglo pasado se han elaborado sobre la corrupción

Vide Nieto García, A. Corrupción en la España Democrática, Ariel, Barcelona, 1997 o Malem SeÑa, J. F. Globalización, comercio internacional y corrupción, Gedisa, Barcelona, 2009, entre otros.

2 Vide Heidenheimer, A. J. Political corruption. Concept and Context, Library of Congress, EEUU, 2001, o JACOBS, J. B. Dilemmas of corruption control, National Institute of Justice, EEUU, 1999. 
en el sector público ${ }^{3}$. Sin embargo, ello no ha logrado consensuar una concepción homogénea de corrupción, ya que cada estudio utiliza su propio concepto autónomo. En palabras de SAJó, "corrupción es un concepto sólidamente establecido, al menos en un sentido: todos sabemos que los expertos nunca coincidirán en una definición única"4.

Ante la abundancia de conceptos teóricos de actos de corrupción, y prescindiendo de definiciones no precisamente jurídicas formuladas por instituciones oficiales (OCDE, Comisión Europea, FMI o RAE), se incluye un concepto jurídico de acuerdo con los trabajos desarrollados por dos autores.

Malem SeÑA, desde el ámbito de la filosofía del derecho, define el acto de corrupción como "violación, activa o pasiva, de un deber posicional o del incumplimiento de un sistema normativo de carácter político, con el objeto de obtener un beneficio extraposicional"5. Será este concepto de corrupción el que habrá de tenerse en cuenta cuando se analicen las medidas contra la misma en la contratación pública. A continuación se describe cada uno de los elementos que incluye esta definición.

$1^{\mathrm{o}}$ - Violación de un deber posicional.

Supone que "quienes se corrompen transgreden algunas de las reglas que rigen el cargo que ostentan o la función que cumplen"6. Dado que se trata de analizar la corrupción en la contratación pública, es necesaria la existencia de un cargo o funcionario público para que el acto de corrupción se produzca. Solamente un cargo o funcionario público puede violar el deber inherente al desarrollo de sus funciones, desde el punto de vista de las buenas prácticas en la actividad pública, en consonancia con la defensa del interés general ${ }^{7}$.

$2^{\circ}$ - Incumplimiento de un marco normativo o político.

Parece adecuado traer aquí a colación a Bustos GisBERT, en tanto que establece una teoría sobre el principal-agente muy oportuna para explicar este aspecto ${ }^{8}$. Así, una conducta concreta será calificada como corrupta "cuando una persona P (políticoagente) que gestiona intereses como consecuencia de una relación de confianza (trust, que emana del electorado-principal), quebranta las normas de conducta [que en ella se

Bustos GiSBERT, R. “Corrupción política: un análisis desde la teoría y la realidad constitucional” en Teoría y realidad constitucional, núm. 25, 2010, pág. 70.

SAJó, A. Political Corruption in Transaction. CEU Press, Budapest - New York, 2002, pág. 2.

MaLEm SEÑA, J. F. “La corrupción política” en Jueces para la democracia, núm. 37, 2000, pág. 27.

Ibidem, pág. 27.

Ibidem, pág. 27.

8 Bustos GiSBERT, R. "Corrupción política: un análisis desde la teoría y la realidad constitucional” en Teoría y realidad constitucional, núm. 25, 2010, págs. 79 y ss. 
establecen]",. En el caso de cargos no elegibles que ejercen funciones públicas, la relación de confianza quebrantada es la otorgada directamente por el que los designó. Por tanto, el marco normativo que establece la definición de MALEM SEÑa estaría constituido tanto por el conjunto del ordenamiento jurídico, como por normas éticas, bien autoacordadas, o bien impuestas por el depositante de confianza.

Bustos Gisbert parte del sistema británico para elaborar este concepto, en el que sí existen normas jurídicas que regulan el comportamiento político ético. En la trasposición de este concepto a España, el marco normativo, aunque se está produciendo un incipiente cambio, en su mayoría está constituido por normas penales. A este respecto, entiende MALEM SEÑa que, en teoría, “cuando además la corrupción pública implica quebrantamiento de normas jurídicas, puede producirse una sanción penal"10.

Es por ello que no todas las conductas de corrupción tendrían necesariamente ese carácter antijurídico ni delictivo, sino que pueden derivar también de un carácter ético. Señala CERRILlo I MARTínEZ, que "no se puede considerar que cualquier irregularidad en la tramitación o gestión de un contrato [público] pueda juzgarse como un caso de corrupción sino cuando existe un uso desviado del poder público por parte de un cargo o empleado público en beneficio propio o personal" $"$.

$3^{\circ}$ - Beneficio extraposicional.

Señala CERRILlo I MARTínez que "puede referirse a la obtención de un beneficio o ganancia directa o indirecta; privada, particular o compartida; personal, familiar o de camarilla; pecuniaria o de estatus" ${ }^{12}$. Pero en cualquier caso, la finalidad, el propósito o la motivación por la que el funcionario o cargo público lleva a cabo dicha violación debe ser la expectativa de obtener un beneficio, que no tiene por qué suponer una ganancia patrimonial. Puede consistir en una amalgama de ganancias de diferente naturaleza.

Finalmente, señalan VILLORIA y JiMÉNEZ una distinción entre dos tipos de corrupción bastante ilustrativa. Por un lado, se encontraría la corrupción política, "aquella en la que están implicados responsables políticos, sean electos o nombrados por razones de confianza política", y por otro la corrupción administrativa, "aquella en la que están implicados funcionarios o empleados públicos, seleccionados, en principio,

\footnotetext{
9 Bustos Gisbert, R. “Corrupción política: un análisis desde la teoría y la realidad constitucional” en Teoría y realidad constitucional, núm. 25, 2010, pág. 82.

10 Malem Seña, J. F. "La corrupción política” en Jueces para la democracia, núm. 37, 2000, pág. 27.

11 Cerrillo I Martínez, A. El Principio de Integridad en la Contratación Pública. Thomson Reuters, Pamplona, 2014, pág. 47.

12 Ibidem, pág. 39.
} 
por criterios meritocráticos y con estabilidad en el puesto" ${ }^{\text {"13. }}$

\subsection{Dimensión y alcance del problema de la corrupción en España}

Según la OCDE, la contratación pública en los Estados parte supone de media en torno a un 13\% del $\mathrm{PIB}^{14}$. En la Unión Europea, en el año 2013, el gasto aproximado relativo a la contratación pública de bienes y servicios ascendió a 1.786,61 miles de millones de euros, un 13,67\% del PIB europeo, lo que supone un incremento del 0,67\% respecto del año anterior ${ }^{15}$.

En 2013 España incurrió en un gasto de 99,60 miles de millones de euros en contratación pública, un 9,74\% del PIB nacional. No obstante, en el contexto reciente de reducción del déficit público, la cantidad invertida en contratación pública ha ido en progresivo descenso, desde el 13,39\% en 2009, pasando por un $12,94 \%$ en 2010 , un $11,83 \%$ en 2011 y un10,18\% en $2012^{16}$.

Teniendo en cuenta el elevado volumen de recursos públicos dedicados a la contratación pública, cobra especial trascendencia cualquier uso inadecuado de los mismos, incluyendo las prácticas corruptas.

A pesar de que no hay estudios que midan directamente los casos de corrupción, ni un consenso sobre cómo medirla, ni si quiera un acuerdo generalizado sobre qué supone un acto de corrupción, se señalan a continuación una serie de indicadores que permitan precisar la dimensión y el alcance de la corrupción en España.

En primer lugar, una aproximación al Barómetro Global de la Corrupción ${ }^{17}$ de 2013, indica que la percepción media de la corrupción ha descendido ligeramente respecto de la encuesta de 2010, produciéndose el mayor descenso en las dos instituciones consideras más corruptas, los partidos políticos y el parlamento ${ }^{18}$. En España se mantiene esa tendencia global de reducción de la percepción de la corrupción, salvo respecto de los partidos políticos, el sistema judicial y el parlamento, que

13 Villoria Mendieta, M. y JimÉnez SÁNCheZ, F. "La corrupción en España (2004-2010): datos, percepción y efectos" en Revista española de investigaciones sociológicas, núm. 138, 2012, pág. 115.

14 OCDE. "Public Procurement for Sustainable and Inclusive Growth". París, pág. 5, 2012. Recuperado el 10 de octubre de 2015 en: http://www.oecd.org/gov/ethics/PublicProcurementRev9.pdf

15 Comisión Europea. "Public Procurement Indicators 2013", 2015, pág. 6. Recuperado el 10 de octubre de 2015 en:

http://ec.europa.eu/DocsRoom/documents/11022/attachments/1/translations/en/renditions/native

16 Ibidem.

17 Se trata de la mayor encuesta a nivel global realizada a 114.000 personas en 107 países sobre experiencias y opiniones de la corrupción, elaborada por TRANSPARENCIA INTERNACIONAL, organización no gubernamental con sede en Berlín

18 Transparencia InTERnACIONALTRANSPARENCIA InTERNACIONAL. "Índices de corrupción Internacional. Barómetro Global de la Corrupción”, 2013. Recuperado el 12 de octubre de 2015 en:

http://transparencia.org.es/bgc-2013/ 
incrementan y se sitúan por encima de la media.

En segundo lugar, según el barómetro del Cis de junio de 2011, el 85,6\% de los españoles cree que la corrupción está muy o bastante extendida, y el 85,9\% cree que existe debido a que la Administración la permite y no la persigue suficientemente ${ }^{19}$. Por otro lado, entre los principales problemas que tiene España, señalan los indicadores del Cis que el relativo al fraude y la corrupción se ha asentado en segunda posición desde febrero de 2013 con más de un $30 \%$ (su techo fue en noviembre de 2014, con un $63,8 \%$ ), solo detrás del paro, a pesar de que suponía un problema casi residual dos años antes, cuando solo un $2,9 \%$ de los encuestados así lo entendía ${ }^{20}$.

En tercer lugar, según el Informe sobre la lucha contra la corrupción en la UE, “el $52 \%$ de los encuestados españoles que respondieron a una encuesta Flash Eurobarómetro sobre las empresas realizada en 2013 consideró que la única manera de triunfar en el mundo empresarial es disponer de contactos políticos (media de la UE: 47 $\%$ ). El $97 \%$ de las empresas españolas (segundo porcentaje más elevado de la UE) declaró que la corrupción está muy extendida en su país (media de la UE: 75 \%), mientras que el $88 \%$ (segundo porcentaje más elevado de la UE) consideró que la corrupción y el abuso de poder están extendidos entre los políticos, los representantes de los partidos o los altos cargos a nivel regional o local (media de la UE: $70 \%$ ). El $93 \%$ de los participantes españoles en esa misma encuesta (segundo porcentaje más elevado de la UE) manifestó que el favoritismo y la corrupción obstaculizan la competencia empresarial en su país (media de la UE: $73 \%$ )"21.

Sin embargo, este mismo informe señala que la percepción de la corrupción en España puede verse agravada y algo alejada de la situación real. Desde la recesión de 2008, el país ha vivido una gran crisis económica, marcada en los últimos años por un la necesidad de ajustes económicos derivados de políticas de reducción del déficit público. Pero el periodo expansivo anterior dio lugar a inversiones en grandes infraestructuras y un elevado gasto público en construcción y desarrollo urbanístico. Ello, sumado a la fuerte descentralización de la estructura política del país ${ }^{22}$, ha contribuido a la

19 Cis. Barómetro de junio. Estudio núm. 2905, 2011. Recuperado el 15 de octubre de 2015 en: http://www.cis.es/cis/export/sites/default/-Archivos/Marginales/2900_2919/2905/Es2905.pdf

20 Cis. "Indicadores. Principales problemas que tiene España", 2015. Recuperado el 4 de diciembre de 2015 en: http://www.cis.es/opencms/-Archivos/Indicadores/documentos html/TresProblemas.html

21 COMISIÓN EUROPEA. "Informe sobre la lucha contra la corrupción", 2014, pág. 5. Recuperado el 8 de octubre de 2015 en: http://europa.eu/rapid/press-release_IP-14-86_es.htm

22 En España, los Ayuntamientos y Alcaldes disponían de amplias competencias en materia de planificación urbana, incluyendo la recalificación del suelo y los procedimientos de contratación pública, aunque buena parte de estas se vieron limitadas mediante la reforma de la Ley 27/2013, de 27 de diciembre, de racionalización y sostenibilidad de la Administración Local. 
propagación de los actos de corrupción pública en los sectores de la planificación urbana y la construcción.

En este mismo sentido apuntan VILLORIA y JiMÉNEZ ${ }^{23}$. En los últimos años, los medios de comunicación han señalado de manera recurrente numerosos casos y variadas noticias sobre actos de corrupción en el ámbito de la contratación que afectan a diversas instituciones públicas, lo cual ha acabado afectando a la percepción existente de la misma y ha derivado en una desafección institucional ${ }^{24}$.

Dicho todo ello, los datos señalan que la corrupción pública en España es esencialmente corrupción política, puesto que "el ratio de criminalidad, aunque sea aproximadamente, es casi de 100 a 1 entre políticos y empleados públicos”25. Asimismo, la corrupción sufrida en España en los últimos años se produjo en el ámbito local y en relación con el urbanismo, debido, en parte, a que los alcaldes ostentaban gran poder de decisión en esta área, de gran discrecionalidad y con bajos controles.

En suma, señalan VILLORIA y JiMÉNEZ que el panorama actual en España refleja un "círculo vicioso de desconfianza que se autoalimenta". La lucha contra la corrupción revela nuevos casos que hacen incrementar la percepción de corrupción y desembocan en "desafección institucional, desapego político", así como en una sensación de corrupción generalizada ${ }^{26}$. Pero la corrupción percibida es mayor que la que los datos puedan sustentar, ya que la corrupción en España es principalmente política y no funcionarial, en la administración local y en relación con el urbanismo ${ }^{27}$.

\subsection{Situación de la regulación de la contratación pública en España}

\subsubsection{Evolución y características de la normativa vigente}

La contratación pública es un elemento básico del ordenamiento jurídico de cualquier Estado, especialmente si pertenece a la UE, no solo por el volumen de recursos que a él se destinan ${ }^{28}$, sino por su apertura al mercado único europeo. Es por

23 Villoria Mendieta, M. y JimÉnEz SÁnchez, F. "La corrupción en España (2004-2010): datos, percepción y efectos” en Revista española de investigaciones sociológicas, núm. 138, 2012, pág. 109.

24 En relación con los medios de comunicación, cabe señalar que la percepción general de la corrupción se encuentra influida en gran medida por la cobertura mediática, ya que es el único modo de que llegue a los ciudadanos información sobre los actos de corrupción política. Por ello, aun manteniéndose inalterado el nivel de corrupción, puede aumentar su percepción. Así, cuando se persigue la corrupción, los escándalos políticos pueden generar la sensación de aumento de la corrupción respecto del momento anterior en que no se perseguía, aunque la realidad presente sea otra. De ahí que VILLORIA y JiMÉNEZ mencionen el "retraso de los efectos" o "lag times" (Ibidem, pág. 117).

25 Ibídem, pág. 121.

26 Ibidem, pág. 129.

27 Cerrillo I Martínez, A. El Principio de Integridad en la Contratación Pública. Thomson Reuters, Pamplona, 2014, pág. 45.

28 Vide apartado 2.2. Dimensión y alcance del problema de la corrupción en España, pág.s 11 y ss. 
ello que resulta necesaria una especial seguridad jurídica para que los operadores económicos desarrollen su tarea en este ámbito de la manera más eficiente posible. Sin embargo, el legislador español no ha tenido muy en cuenta el principio de durabilidad de las normas jurídicas en dicho ámbito ${ }^{29}$.

Cuando España se incorporó a la CEE el 1 de enero de 1986, se encontraban en vigor la Ley de bases de contratación del Estado, de 1963, y su Texto articulado de 1965. Tras la fecha señalada, España se vio obligada a adaptar inmediatamente la legislación de contratos del Estado ${ }^{30}$ a las directivas comunitarias ${ }^{31}$.

Posteriormente, la Ley 13/1995, de 18 de mayo, de contratos de las administraciones públicas, derogó de forma expresa todas las leyes anteriores sobre contratos del Estado y se postuló como una ley general de carácter básico para todas las administraciones públicas del Estado ${ }^{32}$. Esta norma fue modificada en varias ocasiones, destacando la reforma de la Ley 53/1999, de 28 de diciembre, cuya la finalidad era mejorar la objetividad y transparencia en la adjudicación y simplificar procedimientos.

El Texto refundido de la ley de contratos de las administraciones públicas (Real Decreto Legislativo 2/2000, de 6 de junio), que aglutinó en un solo texto las reformas de la ley anterior, se derogó por la Ley 30/2007, de 30 de octubre, de contratos del sector público, la cual trajo causa de la trasposición de una directiva comunitaria ${ }^{33}$. A partir de su publicación, se aprobaron innumerables modificaciones normativas, por lo que en 2011 se hizo necesario elaborar un nuevo texto refundido que las integrara, lo que dio origen al actualmente vigente Real Decreto Legislativo 3/2011, de 14 de noviembre, de la ley de contratos del sector público ${ }^{34}$.

29 Cano Larrotcha, J. "La inminente adaptación de la Ley de Contratos del Sector Público a las nuevas Directivas comunitarias", en Abogados y Consultores de Administración Local, 2015. Recuperado el 1 de octubre de 2015 en: http://www.acalsl.com/blog/2015/03/la-inminente-adapacion-de-la-ley-de-contratos-del-sectorpublico-a-las-nuevas-directivas-comunitarias

30 España se adaptó a las Directivas 71/305/CEE, del Consejo, de 26 de julio de 1971 y 77/62/CEE, del Consejo, de 21 de diciembre de 1976, sobre coordinación de los procedimientos de adjudicación de los contratos públicos de obras y de suministro, respectivamente, mediante el Real Decreto Legislativo 931/1986, de 2 de mayo, por el que se modifica la ley de contratos del Estado para adaptarla a las directivas de la Comunidad Económica Europea.

31 Razquin Lizarraga, M. M. Contratos públicos y Derecho comunitario. Aranzadi, Pamplona, 1996, págs. $103-113$.

32 La Ley 13/1995 traspuso al ordenamiento español las Directivas 93/36/CEE y 93/37/CEE sobre contratos de suministro y obras, respectivamente, a pesar de que el plazo límite se fijó el 14 de junio de 1994.

33 La Ley 30/2007, de 30 de octubre, de contratos del sector público y la Ley 31/2007, de 30 de octubre, sobre procedimientos de contratación en sectores especiales, traspusieron al derecho español las Directivas 2004/18/CE y 2004/17/CE, aunque la fecha límite para ello finalizó el 31 de enero de 2006.

34 De la Morena LóPez, J. "Evolución histórica de la contratación pública en España”, en Observatorio de Contratación Pública, 2012. Recuperado el 10 de septiembre de 2015 en:

http://www.obcp.es/index.php/mod.opiniones/mem.detalle/id.57/relcategoria.121/relmenu.3/chk.e2db6 
Así pues, desde que España pasó a formar parte de la CEE, su ordenamiento, con el fin de adaptarse a las directrices europeas en la mayoría de los casos, ha conocido cinco leyes sobre contratación pública, cada una de una duración media de seis años. Teniendo en cuenta las incontables modificaciones legislativas durante la vigencia de cada una, se ha generado cierto desconcierto en cuanto al procedimiento de contratación pública provocado por la falta de cohesión de un texto numerosamente parcheado, generando cierto grado de inseguridad jurídica ${ }^{35}$.

Esta cambiante y, en ocasiones, confusa regulación de la contratación pública supone un caldo de cultivo para la proliferación de prácticas corruptas, en tanto que se dificulta enormemente la publicidad y claridad de los procesos de contratación, así como los controles preventivos o reparadores en su adjudicación y ejecución.

\subsubsection{Directivas pendientes de trasposición y Anteproyecto de LCSP}

A pesar de que la regulación de la contratación pública debería ser un eje estructural que ofreciera estabilidad y seguridad jurídica, España está en camino de su sexta ley de contratación pública de los últimos treinta años. El 17 de abril de 2015 el Consejo de Ministros aprobó el Anteproyecto de la Ley de Contratos del Sector Público y el de Contratos en los sectores del agua, la energía y los transportes y los servicios postales. Ambos se encuentran actualmente en fase de informes antes de su remisión a las Cortes Generales. No obstante, conforme al panorama resultante tras las últimas elecciones generales, se desconoce el alcance futuro de dichos documentos.

El principal objetivo de estos textos es la trasposición de la cuarta generación de directivas sobre contratación pública ${ }^{36}$, suponiendo, en palabras de MoRENo MoLINA, un “importante salto cualitativo respecto a la regulación anterior, [siendo incluso] más respetuosos con el Derecho europeo hasta el punto de ser incluso más garantista en [diferentes] aspectos" ${ }^{37}$.

\section{ab74524409a96997ab947dc3075}

35 Ibidem.

36 La cuarta generación de directivas en materia de contratación pública está formada por tres de ellas. Se incorporan en el Anteproyecto LCSP dos, la Directiva 2014/23/UE, relativa a la adjudicación de contratos de concesión, y la 2014/24/UE, sobre contratación pública, ambas del Parlamento Europeo y del Consejo, de 26 de febrero de 2014. La trasposición de la Directiva 2014/25/UE, relativa a la contratación por entidades que operan en los sectores del agua, la energía, los transportes y los servicios postales, se producirá específicamente en otra ley. La entrada en vigor de las directivas se produjo el 18 de abril de 2011, 20 días después de su publicación en el DOUE, fecha diferente del plazo de trasposición, que es de dos años y finaliza el 18 de abril de 2016.

37 Moreno MolinA, J. A. "El anteproyecto de nueva ley de contratos del sector público y su imprescindible aprobación" en Observatorio de Contratación Pública, 2015. Recuperado el 26 de septiembre de 2015 en:

http://www.obcp.es/index.php/mod.opiniones/mem.detalle/id.147/relcategoria.208/relmenu.3/chk.1bb2 
La exposición de motivos del Anteproyecto de LCSP señala, de forma acertada según Moreno Molina, que no solo se limita a la trasposición del Derecho europeo, sino que pretende "diseñar y ejecutar un nuevo sistema de contratación pública, más eficiente, transparente e íntegro, mediante el cual se consiga un mejor cumplimiento de los objetivos públicos" ${ }^{\prime 3}$.

Incluye varios aspectos novedosos, algunos de los cuales guardan relación con el objeto de este trabajo. Por una parte, se recoge por primera vez de manera expresa el principio de integridad en el primer artículo ${ }^{39}$, con lo que se positiviza este principio que pretende solucionar las situaciones de conflictos de intereses en el sector público. Por otra parte, se incluye en el ámbito subjetivo a los partidos políticos, las sindicatos y organizaciones empresariales, para los contratos SARA, si tienen financiación pública mayoritaria, lo cual implica un mayor control sobre estas instituciones. Ello, sin duda, ofrece más garantías de supervisión respecto al destino de la financiación pública.

En relación con los procedimientos de contratación, se elimina el de negociado sin publicidad por razón de la cuantía ${ }^{40}$, que no contaba con amparo de la normativa europea, lo cual supone una mejora en la libre concurrencia e igualdad del procedimiento de adjudicación, disminuyendo además la opacidad que dicho sistema implicaba. Asimismo, una de las medidas que incrementa la transparencia y publicidad incluye la eliminación de la obligatoriedad de las Instrucciones Internas de Contratación para los que no sean poder adjudicador, actualmente establecido en el art. 191 TRLCSP, lo que permitirá igualar pautas de contratación pública ${ }^{41}$.

En lo relativo a las directivas aún pendientes de trasposición, es reseñable que por primera vez se realiza una regulación europea de todas las fases del proceso de contratación pública, desde la preparación y adjudicación de los contratos, hasta su ejecución o resolución. Asimismo, se intenta simplificar, actualizar y perfeccionar el procedimiento contractual en la $\mathrm{UE}^{42}$, sirviéndose del mismo para promocionar,

\section{7c7d9cb09535137ea30840a2e13}

\section{Ibidem.}

39 Art. 1 ALCSP: “1. La presente ley tiene por objeto regular la contratación del sector público [...] en conexión con [...] el principio de integridad”.

40 El art. 166 del ALCSP no incluye las disposiciones vigentes en los arts. 171.d, 172.b, 173.f, 174.e y 175 TRLCSP, que permiten la adjudicación mediante un procedimiento negociado sin publicidad de un contrato cuando su valor estimado sea inferior a la cantidad en ellos establecida.

41 Exposición de motivos del Anteproyecto de LCSP: "En el Libro III se mantiene la regulación de los contratos de poderes adjudicadores, no Administración Pública, así como del resto de entes del sector público que no tengan el carácter de poderes adjudicadores, respecto de los cuales se suprime la obligación de aprobar Instrucciones de Contratación."

42 Un ejemplo de simplificación del procedimiento sería el documento único europeo en forma de declaración responsable que el art. 59 de la Directiva 2014/24/UE permite presentar a los licitadores en sustitución de certificados nacionales. 
mediante su valoración en la fase de adjudicación, los objetivos estratégicos de la $\mathrm{UE}^{43}$, como son la protección del medio ambiente, el uso eficiente de la energía, el fomento de la innovación y la inclusión social o el fomento de las PYMES ${ }^{44}$. Se produce un nuevo diseño de políticas públicas, entendido la contratación pública de manera estratégica como una herramienta para fomentar fines concretos que se exigen mediante criterios de solvencia técnica de la oferta ${ }^{45}$.

Asimismo, se hace por primera vez referencia a la prevención de los conflictos de intereses en la contratación pública en el art. 24 de la Directiva 2014/24/UE, estableciendo una definición de conflicto de intereses, la cual es incluida en el art. 64 del Anteproyecto de $\operatorname{LCSP}^{46}$. A pesar de la inconcreción de la redacción del precepto, no deja de ser un gran avance la inclusión del mismo, ya que, según indica CERRILlo I MARTínez, "en la mayoría de los casos, la corrupción surge cuando un interés privado, en una situación considerada como conflicto de intereses, influye indebidamente en el ejercido de las funciones públicas" ${ }^{47}$.

Las nuevas directivas sobre contratación pública deberían ser traspuestas al ordenamiento español antes del 18 de abril de 2016. Hasta esa fecha, si no se ha adaptado la normativa interna, las directivas despliegan un efecto interpretativo que, si bien no es general $^{48}$, lo será hasta tal punto que preserve el efecto útil de la nueva regulación ${ }^{49}$.

43 A modo de ejemplo, el art. 77 Directiva 204/24/UE determina que para valorar la oferta económicamente más ventajosa deberá tenerse en cuenta la calidad de la oferta, para lo cual habrá que evaluar, entre otras, "las características sociales, medioambientales e innovadoras" de la misma. Actualmente se recogen vagamente estos criterios de valoración en el art. 150 TRLCSP, los cuales se incluyen sin grandes cambios en el art. 145 del Anteproyecto LCSP.

44 Moreno MolinA, J. A. "El anteproyecto de nueva ley de contratos del sector público y su imprescindible aprobación” en Observatorio de Contratación Pública, 2015. Recuperado el 26 de septiembre de 2015 en:

http://www.obcp.es/index.php/mod.opiniones/mem.detalle/id.147/relcategoria.208/relmenu.3/chk.1bb2 67c7d9cb09535137ea30840a2e13

45 Gimeno Feliu, J. M. "Reforma de la normativa europea sobre contratación administrativa y transparencia en la contratación por parte del sector público" en Seminario sobre Transparencia administrativa y protección de los intereses financieros de la Unión Europea en la Eurorregión Galicia-Norte de Portugal, págs. 4 - 5, 2014. Recuperado el 15 de octubre de 2015 en: http://egap.xunta.es/recursos/pdf/[1_1399371138]03.pdf

46 Art. 24: "El concepto de conflicto de intereses comprenderá, al menos, cualquier situación en la que los miembros del personal del poder adjudicador, o de un proveedor de servicios de contratación que actúe en nombre del poder adjudicador, que participen en el desarrollo del procedimiento de contratación o puedan influir en el resultado de dicho procedimiento, tengan, directa o indirectamente, un interés financiero, económico o personal que pudiera parecer que compromete su imparcialidad e independencia en el contexto del procedimiento de contratación."

47 Cerrillo I Martínez, A. El Principio de Integridad en la Contratación Pública. Thomson Reuters, Pamplona, 2014, pág. 30.

48 STJUE de 4 de julio de 2006, asunto Adeneler (TJCE 2006\181), apartados 108, 109 y 111.

49 Gimeno Feliu, J. M. "Los efectos jurídicos de las directivas de contratación pública ante el vencimiento del plazo de transposición sin nueva ley de contratos públicos" en Observatorio de 
Gimeno Feliu señala que se trataría de "un deber jurídico de abstención a realizar interpretaciones que puedan comprometer gravemente el éxito de las directivas ya en vigor" ${ }^{\circ 0}$, el cual parece estar dirigido a los operadores jurídicos aplicadores de las normas. El único límite que plantea esta doctrina del TJUE es el de seguridad jurídica, por lo que la interpretación no podrá ser contra legem.

Por otra parte, la STJUE de 8 de octubre de 1987, asunto Kolpinghuis Nijmegen, señala que los Estados deben abstenerse de adoptar disposiciones que puedan comprometer gravemente el contenido de la directiva, por lo que el deber de abstención opera también hacia los creadores de normas jurídicas ${ }^{51}$. Esta misma argumentación la defiende la Abogacía del Estado en uno de sus informes ${ }^{52}$.

Dicho todo ello, se puede afirmar que existe ya cierta fuerza jurídica de las directivas de contratación pública en vigor, conforme a las que se debe reinterpretar la normativa nacional, con el fin de no frustrar la finalidad futura de las directivas. Asimismo, existe el deber de abstención de crear nuevas normas contrarias a las directivas. Finalmente, se deben aplicar directamente disposiciones de las directivas que "refuercen las previsiones de las anteriores directivas o si son plasmaciones de la doctrina del TJUE" 53 .

\section{PRINCIPIOS DE LA CONTRATACIÓN PÚBLICA}

La contratación pública supone una parte de la actividad administrativa, por lo que se encuentra sometida a una serie de principios que deben ser respetados, como consecuencia del sometimiento a los intereses generales que propugna el art. $103 \mathrm{CE}$. El art. 1 TRLCSP $^{54}$ recoge expresamente una serie de principios que serán aplicables a todos los contratos del sector público, con independencia de su naturaleza administrativa

Contratación Pública, 2015. Recuperado el 26 de septiembre de 2015:

http://www.obcp.es/index.php/mod.documentos/mem.descargar/fichero.documentos 7\%232E\%231 J\%232E \%23M Gimeno\%232E\%23 pdf 4b46c93e\%232E\%23pdf/chk.06139d94938569f1561537cef873c101

50 Ibidem.

51 Ibidem.

52 Abogacía del Estado. Informe 3/2015, de 27 de enero de 2015, págs. 13 - 15.

53 Gimeno Feliu, J. M. "Los efectos jurídicos de las directivas de contratación pública ante el vencimiento del plazo de transposición sin nueva ley de contratos públicos" en Observatorio de Contratación Pública, 2015. Recuperado el 26 de septiembre de 2015: http://www.obcp.es/index.php/mod.documentos/mem.descargar/fichero.documentos_7\%232E\%231_J\%232E \%23M_Gimeno\%232E\%23_pdf_4b46c93e\%232E\%23pdf/chk.06139d94938569f1561537cef873c101

54 Art. 1 TRLCSP: "La presente ley tiene por objeto regular la contratación del sector público, a fin de garantizar que la misma se ajusta a los principios de libertad de acceso a las licitaciones, publicidad y transparencia de los procedimientos, y no discriminación e igualdad de trato entre los candidatos, y de asegurar, en conexión con el objetivo de estabilidad presupuestaria y control del gasto, una eficiente utilización de los fondos [...]". 
o privada, su cuantía y la fase del procedimiento que se trate. Asimismo, la Directiva 2014/24/UE promueve en su art. 18 los principios de igualdad, no discriminación, transparencia y libre competencia.

Estos principios están vinculados a los contratos del sector público de manera transversal, por lo que regirán todas las fases de un contrato público, desde la preparación hasta su extinción, con independencia de que sea SARA o no y de la naturaleza del órgano adjudicador.

A continuación, se señalan y describen los principios que en este ámbito guardan relación con el objeto de este trabajo. Posteriormente, se señalarán una serie de medidas para restringir la práctica de actos de corrupción en relación con algunos de ellos.

\subsection{Objetividad}

A pesar de que no se incluye expresamente como principio de la contratación pública en el TRLCSP ni en la normativa europea, ha sido incluida como tal por la doctrina y la jurisprudencia ${ }^{55}$, además de mencionarse como elemento fundamental en varios preceptos normativos ${ }^{56}$. El principio de objetividad busca que se identifique la actividad que lleva a cabo la administración pública con el interés general en exclusiva, sin que se guíe o se vea influida por intereses particulares ${ }^{57}$. De acuerdo con BERNAL BLAY, "en los contratos públicos, el principio de objetividad adquiere su sentido al identificar un vínculo, directo o indirecto, con el objeto de los mismos, abstrayendo las cuestiones que afectan a los elementos personales de la relación" ${ }^{58}$.

Según Cerrillo I Martínez, la objetividad precisa de la existencia de dos elementos ${ }^{59}$. En primer lugar, es necesario que la actuación de la administración se ajuste

55 MoRell OCAÑa considera que la objetividad es un término procedente de la ética, pero que al incorporarse positivamente al Derecho, su vulneración deriva en una conducta antijurídica y no meramente ética (Morell OCAÑA, L. "La objetividad de la Administración Pública y otros componentes de la ética de la institución" en Revista Española de Derecho Administrativo, núm. 111, 2001, págs. 347 - 372). CerRILlo I MarTínez menciona el principio de objetividad como uno de los "principios que guía la actuación de los poderes públicos y que también tiene su reflejo en la contratación pública" (Cerrillo I Martínez, A. El Principio de Integridad en la Contratación Pública. Thomson Reuters, Pamplona, 2014, pág. 160). La STS (Sala de lo Contencioso Administrativo, Sección7 $7^{\mathrm{a}}$ ) de 17 julio de 2012 (RJ 201217912) señala la necesidad de que los criterios en los que se basa la adjudicación cumplan con la nota de objetividad.

56 Vide art. 103 CE, arts 152 y 163 TRLCSP, art. 3 LRJPAC y art. 3 Ley 40/2015, de 1 de octubre, de Régimen Jurídico del Sector Público (en vigor a partir del 2 de octubre de 2016).

57 Cerrillo I Martínez, A. El Principio de Integridad en la Contratación Pública. Thomson Reuters, Pamplona, 2014, pág. 160.

58 Bernal Blay M. A. "El principio de objetividad en la contratación pública", en Documentación Administrativa, núm. 289, 2011, pág. 132.

59 Cerrillo I Martínez, A. El Principio de Integridad en la Contratación Pública. Thomson Reuters, Pamplona, 2014, pág. 160. 
a los fines que el ordenamiento adscribe a la potestad específica que en cada caso se ejerza. En segundo lugar, que la actividad se desarrolle con preponderancia de los intereses generales que motiva la actividad administrativa, sin que influya la voluntad individual del empleado o cargo público.

En todas las fases del proceso de adjudicación de un contrato público debe estar presente el principio de objetividad. No obstante, donde juega un papel más relevante es en las fases de preparación del contrato, valoración de las ofertas y adjudicación final, puesto que es cuando se elige el operador concreto que ejecutará el contenido del contrato. Asimismo, también guarda una estrecha relación en las situaciones de modificación de las condiciones de un contrato ya adjudicado, pero ello se tratará más adelante $^{60}$.

La preparación de los pliegos del contrato público determina las condiciones que obligatoriamente deberán cumplir los candidatos para acceder a la licitación. El art. 54 TRLCSP determina las condiciones de aptitud que cada candidato debe cumplir con independencia del tipo de procedimiento que se trate. Se incluye la necesidad de cumplimiento de los criterios de solvencia económica, financiera y técnica, los cuales son establecidos por el órgano de contratación ${ }^{61}$, pero no arbitrariamente, sino que deben guardar relación con el objeto del contrato. Específicamente, en el caso del procedimiento restringido, el art. 163 TRLCSP indica expresamente que esos criterios de solvencia deben ser objetivos, lo cual parece justificado dado que la solvencia es un criterio de admisión y a la vez de selección ${ }^{62}$.

A este respecto, cabe señalar que el principio de objetividad es un instrumento garante del cumplimiento de otros principios, tales como el de igualdad de acceso a las licitaciones y no discriminación. Señala la STS de 10 de octubre de 2012 que la definición del objeto cierto del contrato, con cumplimiento de lo recogido en los arts. 1261.2, 1271 y $1271 \mathrm{CC}$, permite el "conocimiento concreto del mismo a todos los posibles licitadores en condiciones de igualdad"63. Ello posibilita que formulen sus respectivas ofertas de licitación desde la misma casilla de salida, sin que pueda verse afectado alguno por algún tipo de asimetría de información.

Para controlar la objetividad en esta fase, es esencial el mecanismo del recurso

Vide apartado 4.1.3. Limitación del ius variandi, págs. 39 y ss.

61 Art. 62 TRLCSP.

62 Bernal Blay M. A. "El principio de objetividad en la contratación pública", en Documentación Administrativa, núm. 289, 2011, pág. 137.

63 STS (Sala de lo Contencioso Administrativo, Sección7 ${ }^{a}$ ) de 10 de octubre de 2012 (RJ 201219809), fundamento jurídico $8^{\circ}$. 
especial en materia de contratación pública, mediante el que se puede controlar, entre otras cosas, que los criterios establecidos en los pliegos de contratación guarden relación con la finalidad de contratación establecida en el preceptivo informe previo de necesidad de contratación (art. 22 TRLCSP).

Por otra parte, en la fase de valoración de las ofertas presentadas por los licitadores, es imprescindible que los criterios que utilice la Mesa de contratación sean objetivos $^{64}$. Respecto a la legislación vigente, el art. 150 TRLCSP incluye una lista no exhaustiva de criterios de adjudicación considerados objetivos, tales como la calidad, el precio, la fórmula para revisión de retribuciones ligadas a la utilización de la obra o el plazo de ejecución, entre otros ${ }^{65}$.

En este sentido, el TJUE, en la sentencia de 17 de septiembre de 2002, señaló la necesidad de que los criterios de adjudicación que se apliquen para la elección del adjudicatario deben guardar relación con el objeto del contrato, dado que las ofertas no pueden sino referirse al objeto del mismo para que sean tenidas en cuenta ${ }^{66}$.

Finalmente, no se puede obviar que la objetividad en la contratación pública se encuentra estrechamente ligada con la imparcialidad. Se refiere al deber de todo operador público de actuar ecuánime y objetivamente, en el sentido de no otorgar un trato diferente al que exige el cumplimiento de las normas ${ }^{67}$. Será necesario, por una parte, respetar la relación de agencia en la contratación pública respecto del objeto del contrato $^{68}$, y por otra, garantizar el servicio al interés general en la aplicación de la legalidad, evitando un desvío del servicio al interés público en favor del interés propio de quien toma la decisión ${ }^{69}$.

\subsection{Igualdad de acceso a licitaciones y no discriminación}

Este principio general de la contratación pública aparece expresamente en los arts. 1 y 139 TRLCSP, y en el art. 18 de la Directiva 2014/24/UE, siendo esencial por

64 Esto se recogía en el considerando núm. 46 de la Directiva 2004/18 y se reproduce en el núm. 90 de la Directiva 2014/24/ UE: "La adjudicación de los contratos debe basarse en criterios objetivos que garanticen el respeto de los principios de transparencia, no discriminación e igualdad de trato con el fin de garantizar una comparación objetiva del valor relativo de los licitadores que permita determinar, en condiciones de competencia efectiva, qué oferta es la oferta económicamente más ventajosa".

65 Bernal Blay M. A. "El principio de objetividad en la contratación pública", en Documentación Administrativa, núm. 289, 2011, pág. 141.

66 STJUE de 17 de septiembre de 2002, asunto Concordia Bus Finlad, apartados 59 y 64.

67 Cerrillo I Martínez, A. El Principio de Integridad en la Contratación Pública. Thomson Reuters, Pamplona, 2014, pág. 161.

68 Sobre la relación de agencia, vide apartado 2.1.Concepto de corrupción, pág. 8.

69 Morell OcAÑA, L. "La objetividad de la Administración Pública y otros componentes de la ética de la institución” en Revista Española de Derecho Administrativo, núm. 111, 2001, págs. 347 - 372. 
representar además uno de los principios inspiradores del mercado único europeo, quedando plasmado en el TFUE ${ }^{70}$. Se trata de hacer respetar la libre competencia en la contratación pública, del mismo modo que en el sector privado. Para ello, la administración pública no puede llevar a cabo prácticas de discriminación, debiendo respetar en todo proceso administrativo, incluido el de la contratación pública, el equilibrio competitivo del mercado.

Todo ello dota de transversalidad a dicho principio, por lo que no importa qué prestaciones o ente del sector público esté contratando, que tendrá que respetar su contenido $^{71}$. La STJUE de 16 de septiembre de $2013^{72}$ resume claramente este principio:

“66. En concreto, el principio de igualdad de trato entre licitadores, [...] que pretende favorecer el desarrollo de una competencia sana y efectiva entre las empresas que participan en una licitación, impone que todos los licitadores dispongan de las mismas oportunidades al formular los términos de sus ofertas e implica, por tanto, que éstas estén sometidas a las mismas condiciones para todos los competidores [...]. De este modo, la entidad adjudicadora está obligada a respetar, en cada fase del procedimiento de licitación, el principio de igualdad de trato de los licitadores [...], y éstos deben encontrarse en igualdad de condiciones tanto en el momento en que preparan sus ofertas como en el momento en que éstas se someten a la evaluación de la entidad adjudicadora. [...].

67. Por otra parte, el principio de igualdad de trato implica, en particular, una obligación de transparencia para permitir a la entidad adjudicadora garantizar su respeto [...]. El principio de transparencia, que constituye el corolario del principio de igualdad de trato, tiene esencialmente por objeto garantizar que no exista riesgo de favoritismo y arbitrariedad por parte de la entidad adjudicadora."

En definitiva, lo que exige la implementación de este principio en la contratación pública es garantizar que no exista ningún tipo de favoritismo ni arbitrariedad por parte del órgano adjudicador a la hora de seleccionar al contratista. Esto no se puede lograr sin que situaciones comparables reciban un trato similar y se traten de modo idéntico. Para

70 Los arts. 101 y 102 TFUE recogen la prohibición en abstracto de restricción de la competencia del mercado. Lo indica del mismo modo el considerando 1 de la Directiva 2014/24/UE.

71 LÓPEZ MiÑo, A. "Insuficiencia del derecho español para impedir y corregir la colusión en la contratación pública" en Proyecto de investigación "Contratación pública y transparencia: alcance y límites de los principios de publicidad y libre competencia”, 2012, pág. 2.

72 STJUE de 16 de septiembre de 2013, caso España contra Comisión Europea (TJCE\2013\282). 
ello es necesario, pues, que todos los licitadores cuenten con las mismas oportunidades a la hora de formular sus ofertas, es decir, que todos los competidores estén sometidos a las mismas condiciones ${ }^{73}$.

Hasta ahora, este principio se reflejaba en la normativa comunitaria de forma parcial y fraccionada. Por ello, era necesario, según SÁnChEZ GraELls, un "notable esfuerzo interpretativo para delimitar las obligaciones derivadas del mismo"74. Lo mismo ocurría respecto del TRLCSP, que traspuso la normativa europea anterior sin que añadiera nada al respecto. Sin embargo, la Directiva actualmente en vigor introduce en su art. 18 expresamente el principio de competencia ${ }^{75}$. Va más allá de recogerlo meramente dentro de las reglas reguladores de las prescripciones técnicas que recoge simplemente el art. 117 TRLCSP.

Se señalan dos aspectos novedosos por los que, para SÁNCHEZ GraELls, "no será sorprendente que el nuevo artículo 18 de la Directiva 2014/24/UE sea objeto de un nivel significativo de litigiosidad"76. Por un lado, se incluye un elemento puramente subjetivo para determinar la restricción artificial de la competencia, al especificarse la necesidad de que la contratación no será concebida con esa intención. Es harto complejo establecer los parámetros por los que una decisión debe ser considerada tomada con intención anticompetitiva, máxime cuando normalmente son varios sujetos los que están involucrados en la misma.

La solución, entiende SÁNCHEZ GRAELLS, pasa por interpretar el elemento intencional para intentar objetivarlo ${ }^{77}$. Así, una de las posibles medidas sería el establecimiento de una presunción iuris tantum de intención restrictiva de la competencia en los casos que la propia licitación restrinja la competencia (procedimiento negociado, por ejemplo).

73 Cerrillo I Martínez, A. El Principio de Integridad en la Contratación Pública. Thomson Reuters, Pamplona, 2014, pág. 158.

74 SÁnchez Graells, A. "El 'nuevo' principio de competencia en la Directiva 2014/24: ¿un nuevo juego de presunciones?" en Observatorio de Contratación Pública, 2014. Recuperado el 2 de octubre de 2015 en:

http://www.obcp.es/index.php/mod.opiniones/mem.detalle/id.157/relcategoria.121/relmenu.3/chk.2deb 0e818e9d4231ea49db81b85bf449

75 Art. 18.1, párrafo $2^{\circ}$ : "La contratación no será concebida con la intención de excluirla del ámbito de aplicación de la presente Directiva ni de restringir artificialmente la competencia. Se considerará que la competencia está artificialmente restringida cuando la contratación se haya concebido con la intención de favorecer o perjudicar indebidamente a determinados operadores económicos."

76 SÁnchez Graells, A. "El 'nuevo' principio de competencia en la Directiva 2014/24: ¿un nuevo juego de presunciones?" en Observatorio de Contratación Pública, 2014. Recuperado el 2 de octubre de 2015 en: http://www.obcp.es/index.php/mod.opiniones/mem.detalle/id.157/relcategoria.121/relmenu.3/chk.2deb 0e818e9d4231ea49db81b85bf449

77 Ibidem. 
Por otro lado, la directiva establece una presunción iuris et de iure, entendiendo, en palabras de SÁNCHEZ GRAELLS, que la competencia se restringe artificialmente "en los casos en que se haya producido favoritismo (ya derive o no de prácticas corruptas)"78. Esta presunción de intención anticompetitiva para los casos en que se haya incurrido en en favoritismo o discriminación es redundante, puesto que lo establecido en los nuevos preceptos sobre conflictos de interés sería suficiente para cubrir este aspecto.

Pero además, esta precisión podría ser contraproducente, ya que cabría una interpretación de algunos operadores jurídicos que estableciera que en los casos en los que no no haya favoritismo no se pueden dar restricciones a la competencia que vulneren el precepto, lo cual parece no ser lo que se pretende ${ }^{79}$.

\subsection{Eficiencia en el gasto}

La eficiencia en el gasto público, entendida como optimización de los recursos públicos para obtener el máximo rendimiento al menor coste posible, guarda relación con la corrupción. Según el Informe de la UE sobre lucha contra la corrupción, la corrupción genera pérdidas de alrededor de 120.000 millones de euros en la economía de la UE, un $1 \%$ aproximadamente del PIB europeo ${ }^{80}$, lo cual significa que la misma no permite un aprovechamiento óptimo de los recursos disponibles en el sector público, incluyendo la contratación pública.

La necesidad de que el gasto público se realice de forma eficiente ya lo recoge la CE en su art. 31. Sin embargo, dado que las mayores tentaciones de corrupción se producen en el sector de la contratación pública, se ha visto necesario incluirlo tanto en la normativa europea como en la nacional. Por un lado, el considerando $5^{\circ}$ de la Directiva 2014/24/UE señala que uno de los objetivos de la "Estrategia Europa 2020" es conseguir un uso más eficiente de los fondos públicos.

Por otro lado, el art. 22 TRLCSP precisa que los entes del sector público "velarán por la eficiencia y el mantenimiento de los términos acordados en la ejecución de los procesos de contratación pública". En este sentido, se añaden una serie de cuestiones preceptivas, tales como señalar las necesidades que se pretenden cubrir mediante cada contrato público, la idoneidad del objeto para satisfacerlas, o el mantenimiento de los términos acordados en la ejecución, con el fin de que se celebren solamente los contratos

78 Ibidem.

79 Ibidem.

80 COMISIÓN EuROPEA. "Informe sobre lucha contra la corrupción de la UE”, 2014, pág. 3. Recuperado el 13 de octubre de 2015 en: http://europa.eu/rapid/press-release_IP-14-86_es.htm 
necesarios para satisfacer los fines generales.

Para llevar a la práctica estas cuestiones es esencial una adecuada y efectiva transparencia en el proceso de contratación pública ${ }^{81}$. Pero no cabe duda del especial interés en la gestión adecuada y optimización de recursos en un contexto de reducción del déficit público en el que se encuentra España en estos momentos ${ }^{82}$.

Se trata, en definitiva, de un aspecto básico en la contratación del sector público, ya que supone un elevado volumen de recursos económicos, por lo que un uso óptimo de los mismos beneficia a la colectividad. Es, por tanto, una extensión de la buena gestión de los fondos públicos, lo cual choca frontalmente con los actos de corrupción, que no suponen sino una disfuncionalidad en la redistribución de los mismos.

Para ello es necesario un adecuado nivel formativo de los órganos de contratación respecto de los aspectos técnicos de los medios con los que se pretende llevar a cabo la ejecución del contrato, con el fin de selección la oferta económicamente más ventajosa de manera efectiva. Resulta paradójico que el uso eficiente de los recursos públicos no implique necesariamente adjudicar el contrato a la oferta con menor precio.

Así, la eficiencia no consiste en adquirir algo que aparentemente es lo más barato, ya que hay una serie de factores que van a condicionar el gasto final, tales como la calidad, las condiciones de ejecución, la rentabilidad de la prestación o el ciclo de vida de los productos contratados. Todo ello tiene consecuencias presupuestarias, motivo por el cual la normativa europea ha consolidado criterios de adjudicación que no se fijan exclusivamente en el precio. En la nueva generación de directivas se incluyen una serie de factores que se quieren fomentar en la "estrategia europea de contratación 2020"

\subsection{Integridad}

Cada vez más, los ciudadanos exigen a las administraciones públicas mayor información sobre los intereses privados que entran en colisión con la toma de decisiones que afectan al interés general. Se exige que los cargos públicos respeten el cumplimiento las normas para poder otorgar confianza a los poderes públicos, en

81 Vide apartado 3.5. Transparencia y publicidad, págs. 28 y ss.

82 Gimeno Feliu, J. M. "La obligación de publicidad de todas las licitaciones en la plataforma de contratos del sector público" en Observatorio de Contratación Pública, 2014. Recuperado el 2 de octubre de 2015 en:

http://www.obcp.es/index.php/mod.opiniones/mem.detalle/id.153/relcategoria.121/relmenu.3/chk.577429fa 7149b11b2d930ebe5b579d9f

83 Entre otros, el fomento de la innovación, el respeto al medioambiente o la mejora de las condiciones sociales (considerando 47 Directiva 2014/24/UE). 
especial en aquellos sectores donde los niveles de discrecionalidad son mayores e impera la necesidad de controlar la arbitrariedad, como es el caso de la contratación pública ${ }^{84}$.

De ahí surge la necesidad de que la actuación de los poderes públicos derive en una buena gobernanza y administración. Organismos internacionales, como la OCDE, han señalado que la integridad en la contratación pública es vital para retener la confianza de los ciudadanos en el sector público ${ }^{85}$. El principio de integridad, como se ha recogido supra ${ }^{86}$, se ha incorporado en el art. 1 del Anteproyecto de la LCSP, encontrando apoyo expreso en el art. 64 de la Directiva 2014/24/UE sobre el conflicto de interés.

La integridad en la administración pública consiste en la exigencia de "coherencia entre lo previsto por el ordenamiento jurídico y lo efectivamente realizado por los empleados de carácter público, sin que prevalezcan otros intereses o fines particulares por encima del interés general" ${ }^{\prime 7}$.

Señala CERRILlo I MARTíneZ que "la integridad y la corrupción son las dos caras de la misma moneda" puesto que "la corrupción constituye una violación de la integridad" $"$. Por tanto, la integridad como principio de la contratación pública hace referencia a un conjunto de mecanismos que encaucen la conducta de los cargos públicos hacia el respeto del marco normativo de referencia, así como que eviten el surgimiento de conflictos de intereses, facilitando que no se sucumba a la tentación en caso de que exista alguno. Así, existirá integridad en la actividad pública cuando no se produzcan conflictos de intereses o cuando, produciéndose, no deriven en actos de corrupción.

Sin embargo, tal y como indica GiMENo Feliu, para preservar la integridad en la contratación pública, "no basta con una regulación reaccional de carácter penal, que, siendo necesaria, no es suficiente" ${ }^{\text {" }}$. Son precisos muchos más mecanismos

84 Cerrillo I Martínez, A. El Principio de Integridad en la Contratación Pública. Thomson Reuters, Pamplona, 2014, pág. 54.

85 OCDE. "Principles for Integrity in Public procurement", París, 2009, pág. 23. Recuperado el 1 de octubre de 2015 en: http://www.oecd.org/gov/ethics/48994520.pdf

86 Vide apartado 2.3.2. Directivas pendientes de trasposición y Anteproyecto de LCSP, págs. 15 y ss.

87 Cerrillo I Martínez, A. El Principio de Integridad en la Contratación Pública. Thomson Reuters, Pamplona, 2014, pág. 53.

88 Ibidem, pág. 59.

89 Gimeno Feliu, J. M. "La reforma comunitaria en materia de contratos públicos y su incidencia en la legislación española. Una visión desde la perspectiva de la integridad” en Congreso AEPDA, 2015, pág. 46. Recuperado el 5 de octubre de 2015 en: http://www.csital.org/sites/default/files/Pon\%C3\%A8ncia\%20Jos\%C3\%A9\%20Mar\%C3\%ADa \%20Gimeno.pdf 
encaminados a evitar que se produzcan actos de corrupción y que frustren sus posibilidades de surgimiento. Para limitar la existencia de actos de corrupción, la estrategia de prevención es más efectiva que su persecución y combate una vez surgida.

Es necesario prevenir los conflictos de intereses para evitar que surjan situaciones en las que influyan indebidamente los intereses privados y garantizar la equidad en el proceso de toma de decisiones. La legislación española en este ámbito trata de manera diferenciada los conflictos de intereses de los altos cargos y de los empleados públicos ${ }^{90}$.

Por un lado, el Estatuto del alto cargo tiene el objetivo de evitar situaciones que puedan derivar en conflictos de intereses entre los miembros del Gobierno y los altos cargos de la Administración General del Estado. Su art. 11.2 señala que "se entiende que un alto cargo está incurso en conflicto de intereses cuando la decisión que vaya a adoptar [...] pueda afectar a sus intereses personales, de naturaleza económica o profesional, por suponer un beneficio o un perjuicio a los mismos".

La norma prevé una serie de circunstancias para prevenir que se produzca una colisión entre los intereses privados con decisiones o asuntos públicos, tales como la obligación de abstención en la toma de decisiones afectados por aquellos (art. 12), la limitación patrimonial en participaciones societarias (art. 14) o limitaciones al ejercicio de actividades privadas con posterioridad al cese (art. 15). Todo ello va encaminado a evitar que una situación en la que existan intereses contrapuestos derive en una vulneración del principio de integridad.

Por otro lado, el EBEP incorpora en su art. 52 un Código de conducta de los empleados públicos, que aunque no prevé expresamente el conflicto de intereses, incorpora la vigencia de los principios de objetividad, integridad y transparencia en la conducta de los empleados públicos.

No obstante, la integridad debe manifestarse antes, durante y tras la actuación de un alto cargo o un empleado público. Las consecuencias que genera la ausencia de integridad también son distintas, pudiendo derivar en la anulación del acto en cuestión, en sanciones administrativas ${ }^{91} \mathrm{o}$ incluso en condenas penales, en caso de que la conducta esté tipificada como delito. Asimismo, son variadas las situaciones que pueden poner en

90 Cerrillo I Martínez, A. El Principio de Integridad en la Contratación Pública. Thomson Reuters, Pamplona, 2014, pág. 176.

91 Mencionar a título de ejemplo que el art. 26 del Estatuto del alto cargo recoge una serie de sanciones por la comisión de alguna infracción en el mismo tipificada, que van desde la destitución del cargo público, hasta la pérdida del derecho a recibir compensación tras el cese. 
tela de juicio la integridad en la contratación pública ${ }^{92}$.

En la fase de preparación del contrato, se puede considerar carencia de integridad "la falta de una evaluación adecuada de las necesidades o un presupuesto ajustado al contrato público, la inversión no necesaria o injustificada, la no definición adecuada de los objetivos, la inadecuada o irregular elección del procedimiento de contratación o la adjudicación para pagar antiguos favores o para compensar trabajos pasados"93.

En la fase de licitación y adjudicación, "la ausencia de integridad se puede identificar en el acceso irregular a la información de los licitadores, la falta de competencia o en la falta de acceso a los archivos del procedimiento de adjudicación que desalienta a los licitadores no seleccionados a impugnar la decisión"94.

Estos ejemplos son útiles para señalar que no siempre que la integridad no está presente en la contratación pública se producen un conflictos de intereses o ilegalidades. En algunos casos, la escasez de recursos humanos y materiales o la mala organización pueden originar situaciones irregulares. Así, se debe identificar la falta de integridad con la comisión "deliberada, activa y consciente de determinadas actuaciones incumpliendo el marco de referencia" ${ }^{\prime 95}$.

\subsection{Transparencia y publicidad}

Los principios de transparencia y publicidad se refieren al conocimiento efectivo de aspectos relacionados con la toma de decisiones respecto de los contratos públicos y de la información referente a las diferentes fases del proceso de contratación ${ }^{96}$. La transparencia refuerza el principio de integridad, teniendo en cuenta que en ausencia de transparencia real se multiplica el riesgo de que los conflictos de intereses deriven en actos de corrupción, lo que, en definitiva, supone la negación del derecho de una buena administración ${ }^{97}$.

Sin embargo, ambos son principios complementarios. La publicidad consiste en divulgar la actividad de la administración en relación a un determinado proceso de

92 Cerrillo I Martínez, A. El Principio de Integridad en la Contratación Pública. Thomson Reuters, Pamplona, 2014, pág. 59.

93 Ibidem, pág. 61.

94 Ibidem, pág. 62

95 Ibidem, pág. 62.

96 Ibidem, pág. 65.

97 Gimeno Feliu, J. M. "La obligación de publicidad de todas las licitaciones en la plataforma de contratos del sector público" en Observatorio de Contratación Pública, 2014. Recuperado el 2 de octubre de 2015 en:

http://www.obcp.es/index.php/mod.opiniones/mem.detalle/id.153/relcategoria.121/relmenu.3/chk.5774 $\underline{29 \mathrm{fa} 7149 \mathrm{~b} 11 \mathrm{~b} 2 \mathrm{~d} 930 \mathrm{ebe} 5 \mathrm{~b} 579 \mathrm{~d} 9 \mathrm{f}}$ 
contratación, mientras que la transparencia se refiere a la posibilidad de que los ciudadanos en general puedan conocer la actuación de las administraciones públicas, entre las que se encuentra la actividad de contratación pública ${ }^{98}$.

Muchos son los cuerpos normativos que tienen en cuenta el principio de transparencia en su redacción. El TRLCSP lo menciona en el art. 1 como principio general, pero alude a él a lo largo de todo el texto, como en el art. 53.1, para motivar la creación del perfil del contratante, o en el art. 139, donde exige su respeto en el trato de los órganos de contratación con los licitadores.

El Anteproyecto LCSP no se queda atrás y amplía las referencias que hace de la transparencia en la contratación pública, indicando en su art. 132 que "la contratación no será concebida con la intención de eludir los requisitos de publicidad o los relativos al procedimiento de adjudicación que corresponda, ni de restringir artificialmente la competencia, bien favoreciendo o perjudicando indebidamente a determinados empresarios." Asimismo, en su art. 145 la incluye como un requisito para establecer los criterios de adjudicación.

La transparencia también es un eje vertebrador en la Directiva 2014/24/UE, que además de mencionarla como principio, exige que se cumpla a la hora de presentar información tras la solicitud de los operadores económicos (art. 56.3) o a la hora de establecer los anuncios de licitación (art. 48). Igualmente, es mencionado en el Código de conducta del EBEP como un deber del empleado público en el desempeño de sus tareas (art. 52), en la LTAIBG (art. 5) y en otras normas, como en el Estatuto del alto cargo (art. 3) o en la LRJPAC (art. 37).

El principio de transparencia tiene tres vertientes, ya que, como señala CERRILlo I MARTínez "se erige como un principio de la contratación pública estrechamente relacionado con el resto de principios de la contratación"99. Por un lado, permite garantizar la igualdad de todos los licitadores, así como su no discriminación, puesto que posibilita un adecuado conocimiento del ciclo de la contratación, lo cual proporciona un trato equitativo a todos los licitadores ${ }^{100}$. La transparencia es una forma de generar

98 Cerrillo i Martínez, A. El Principio de Integridad en la Contratación Pública. Thomson Reuters, Pamplona, 2014, pág. 107.

99 Ibidem, pág. 103.

${ }^{100}$ La jurisprudencia del TJUE es clara al señalar que la transparencia permite garantizar el respeto del principio de igualdad de trato. Vide como ejemplo la sentencia del Tribunal de Primera Instancia de las Comunidades Europeas (TPICE) de 12 de marzo de 2008, apartado 141. Apunta que "por lo que respecta al principio de transparencia, que constituye su corolario, tiene esencialmente por objeto garantizar que no exista riesgo de favoritismo y arbitrariedad por parte de la entidad adjudicadora. Implica que todas las condiciones y modalidades del procedimiento de licitación estén formuladas de forma clara, precisa e inequívoca en el anuncio de licitación o en el pliego de condiciones". 
competencia y concurrencia empresarial, garantizando a todo licitador potencial abrir el mercado de la contratación pública mediante la publicación del objeto de licitación y las reglas de la misma ${ }^{101}$.

Por otro lado, reafirma el principio de integridad, sobre todo en los procedimientos de adjudicación restringidos. Permite mitigar el peligro de corrupción al minimizar el riesgo de que un conflicto de interés derive en el favorecimiento de la utilidad privada de la adjudicación. Así, limita el riesgo de que la entidad adjudicadora actúe arbitrariamente o se sustente mediante redes clientelares ${ }^{102}$.

Ello es porque, en último lugar, mediante la transparencia se puede conocer con cierto rigor la actividad de la administración pública, lo cual permite llevar a cabo un control sobre las decisiones tomadas en relación con el destino de los fondos públicos ${ }^{103}$.

Este extremo es de vital importancia, puesto que sin medidas que garanticen la transparencia de las administraciones públicas no es tarea fácil recabar información por parte de los órganos de control. Después de todo, la corrupción y los conflictos de intereses se encuentran envueltos por un halo de secretismo a menudo muy difícil de franquear ${ }^{104}$.

Una de las cuestiones básicas que garantizan la transparencia es la necesidad de que las condiciones y el procedimiento de licitación se establezcan de manera clara y precisa en el anuncio de licitación y en el pliego de condiciones. Asimismo, es esencial que se produzca una correcta elección del procedimiento que se va a llevar a cabo. Es necesario que se utilice el procedimiento negociado de manera adecuada, ya que si bien aporta una mayor flexibilidad y simplificación del proceso contractual, es el procedimiento en el que mayor grado de discrecionalidad ostentan los órganos de contratación, lo que supone un riesgo de discriminación o no respecto de criterios objetivos de adjudicación ${ }^{105}$.

101 Gimeno Feliu, J. M. "Decálogo de reglas para prevenir la corrupción en los contratos públicos" en Observatorio de Contratación Pública, 2014. Recuperado el 15 de septiembre de 2015 en: http://www.obcp.es/index.php/mod.opiniones/mem.detalle/id.180/relcategoria.208/relmenu.3/chk.1b2c 9f6d99eecf44223c17ac60720747

102 Gimeno Feliu, J. M. "La reforma comunitaria en materia de contratos públicos y su incidencia en la legislación española. Una visión desde la perspectiva de la integridad" en Congreso AEPDA, pág. 6, 2015. Recuperado el 5 de octubre de 2015 en:

http://www.csital.org/sites/default/files/Pon\%C3\%A8ncia\%20Jos\%C3\%A9\%20Mar\%C3\%ADa \%20Gimeno.pdf

103 Cerrillo I Martínez, A. El Principio de Integridad en la Contratación Pública. Thomson Reuters, Pamplona, 2014, pág. 66.

104 Cerrillo I Martínez, A. El Principio de Integridad en la Contratación Pública. Thomson Reuters, Pamplona, 2014, pág. 257.

105 Gimeno Feliu, J. M. "La obligación de publicidad de todas las licitaciones en la plataforma de contratos del sector público" en Observatorio de Contratación Pública, 2014. Recuperado el 2 de octubre de 2015 en: 
En definitiva, la transparencia y la publicidad son dos principios comunitarios bien asentados en el ordenamiento español fundamentales en la contratación pública, que sirven de base para la creación de un mercado de la contratación pública europeo.

\section{MEDIDAS CONTRA LA CORRUPCIÓN}

La vulneración de alguno de los principios descritos supra en la vida de un contrato público supondrá un acto de corrupción para el caso de que cumpla con la definición seguida en presente documento. Como es conocido por cualquier operador jurídico, un principio general del Derecho incluido en una norma de poco sirve si no existen mecanismos que aseguren su cumplimiento real. En el ámbito de la contratación pública varios son los motivos que dificultan un control exhaustivo de la efectiva vigencia de los mismos en la conducta de los operadores públicos.

Por todo ello, como la positivización de un principio deviene inútil sin la dotación de elementos jurídicos de prevención, control, reparación y, eventualmente, sanción, ante su incumplimiento, es necesario establecer un conjunto de cortafuegos que dificulten lo máximo posible la aparición de actos de corrupción ${ }^{106}$.

A continuación, se analizan una serie de medidas que ofrece nuestro ordenamiento jurídico para ello y se señala su utilidad ${ }^{107}$. Se han clasificado las mismas en función del momento de vida del contrato en el que son efectivas, entendiendo la fase de adjudicación como punto de inflexión. Ello se debe a su extrema importancia, ya que se trata del momento más propenso a la aparición de actos de corrupción.

\subsection{Medidas previas a la adjudicación del contrato}

El control preventivo, que persigue garantizar la vigencia de las condiciones necesarias para evitar que se produzcan actos de corrupción en los procesos de contratación pública, es esencial. Así, como señalaba KAUfMANN, no se puede "combatir la corrupción luchando contra ella" ${ }^{108}$. Para avanzar en su eliminación hay que enfocar

http://www.obcp.es/index.php/mod.opiniones/mem.detalle/id.153/relcategoria.121/relmenu.3/chk.5774 29fa7149b11b2d930ebe5b579d9f

106 A modo de ejemplo, la Exposición de Motivos de la LTAIBG señala que "las normas sectoriales que contienen obligaciones concretas de publicidad activa [...] resulta[n] insuficiente[s] en la actualidad y no satisface[n] las exigencias sociales y políticas del momento".

107 Se trata de medidas en el ámbito del Derecho administrativo, puesto que no es objeto del presente trabajo considerar las infracciones tipificadas en el Código Penal respecto de la corrupción.

108 Kaufmann, D. "Diez mitos sobre la gobernabilidad y la corrupción" en Finanzas \& Desarrollo, 2005, pág. 42. Recuperado el 15 de octubre de 2015 en: 
gran parte de los esfuerzos intentando evitar que surja, lo que supone tomar medidas y poner en práctica mecanismos preventivos eficaces y realistas.

A continuación se describen cuatro mecanismos que recoge el ordenamiento jurídico español encaminados a fomentar la integridad en las fases previas y en la propia adjudicación contractual. El objetivo de los mismos es intentar garantizar que los principios relacionados con la contratación pública no se desvirtúen en una de sus fases más importantes.

\subsubsection{Publicación de información}

La publicación de información relativa la actividad de la administración es un elemento clave a la hora de prevenir la corrupción, pues "corrupción y secreto están estrechamente vinculados" ${ } 109$. El fomento de los principios de publicidad y transparencia supone un buen control y equilibro que evita que surjan actos de corrupción, pues el efecto de los mismos sería su afloramiento inmediato.

Existen una serie de mecanismos mediante los que se intenta hacer efectivos los principios de publicidad y transparencia, con los que se pretende que no sean meras formalidades, sino que sirvan de utilidad para garantizar su vigencia.

No obstante, el alcance del acceso y difusión de la información pública puede colisionar con otros principios, entre los que se encuentra el de confidencialidad ${ }^{110}$. Así, deben respetarse los límites relativos a la protección de datos personales, información que perjudique al interés público o que lesione intereses comerciales o privados, en cuyo caso se prevé la no divulgación de los mismos ${ }^{111}$.

\section{a) Difusión de información}

La primera medida para prevenir la corrupción que se señala en el ámbito de la transparencia es la difusión de información del sector público y su puesta a disposición de los ciudadanos. Se trata de un mecanismo proactivo mediante el cual se publica la actividad de las administraciones públicas para que pueda ser conocida por los

\footnotetext{
https://www.imf.org/external/pubs/ft/fandd/spa/2005/09/pdf/basics.pdf

109 Cerrillo I Martínez, A. "Transparencia administrativa y lucha contra la corrupción en la Administración local" en Anuario del Gobierno Local de la Fundación Democracia y Gobierno Local, 2011, pág. 307.

110 Cerrillo I Martínez, A. El Principio de Integridad en la Contratación Pública. Thomson Reuters, Pamplona, 2014, pág. 142.

111 En este sentido el art. 14 LTAIBG señala unos límites justificados y proporcionales al objeto y finalidad de la protección de la información, tales como el perjuicio a la seguridad nacional, la defensa, la seguridad pública o la política económica y monetaria.
} 
ciudadanos. En este sentido, representa un a gran novedad la LTAIBG, cuyo ámbito subjetivo recogido en el art. 2 incluye a todo el sector público citado en el art. 2 TRLCSP, además de a otras instituciones tales como la Casa de su Majestad el Rey, las Cortes Generales, o el Tribunal de Cuentas, entre otras. Esta actividad se ha facilitado gracias a la proliferación de los medios electrónicos como canal de información en las relaciones con la administración ${ }^{112}$.

Deberán publicar de forma periódica y actualizada la información relacionada con el funcionamiento y control de la actuación pública, de conformidad con el art. 5 LTAIBG. Para que la difusión de dicha información se haga efectiva no es necesaria una previa petición o reclamación de ningún tipo, sino que las entidades mencionadas deben hacerla efectiva de manera obligatoria. Es por ello que se ha extendido el término de "transparencia activa"113.

Entre toda la información cuya publicación se exige, el art. 8.1.a LTAIBG recoge un conjunto de datos muy relevantes respecto de los contratos públicos celebrados por los sujetos incluidos en el ámbito de aplicación de la ley ${ }^{114}$. Asimismo, el art. 7.a LTAIBG recoge la obligación de difundir información tanto desde el punto de vista de los contratos públicos como de los conflictos de interés que se puedan generar ${ }^{115}$.

Ello implica que no solo los interesados en un proceso de contratación (licitadores, en su mayoría) tendrán derecho a conocer las circunstancias del mismo, en especial de la adjudicación. Cualquier persona o entidad podrá acceder a dicha información, aunque no haya participado en el proceso ${ }^{116}$.

112 La Ley 11/2007, de 22 de junio, de acceso electrónico de los ciudadanos a los servicios públicos (vigente hasta el 2 de octubre de 2016, fecha en la que entra en vigor la Ley 39/2015, de 1 de octubre, del procedimiento administrativo común de las administraciones públicas) ha supuesto un salto cualitativo en la regulación de la difusión de la información. Mejora la accesibilidad y la calidad de la información publicada, establece la responsabilidad que pueda generar la difusión de datos erróneos y reconoce el derecho de los ciudadanos a relacionarse con la administración por vía electrónica, entre otras cuestiones (Cerrillo I Martínez, A. El Principio de Integridad en la Contratación Pública. Thomson Reuters, Pamplona, 2014, pág. 109).

113 RazQuin Lizarraga, M. M. "Llega la transparencia” en Observatorio de Contratación Pública, 2015. Recuperado el 18 de noviembre de 2015 en:

http://www.obcp.es/index.php/mod.opiniones/mem.detalle/id.216/relcategoria.121/relmenu.3/chk.432d 81119283a4d5d1b8f36f34844888

114 Entre los que se encuentran los datos relativos a "todos los contratos, con indicación del objeto, duración, el importe de licitación y de adjudicación, el procedimiento utilizado para su celebración, los instrumentos a través de los que, en su caso, se ha publicitado, el número de licitadores participantes en el procedimiento y la identidad del adjudicatario, así como las modificaciones del contrato".

115 "Las directrices, instrucciones, acuerdos, circulares o respuestas a consultas planteadas por los particulares u otros órganos en la medida en que supongan una interpretación del Derecho o tengan efectos jurídicos."

116 RazQuin Lizarraga, M. M. "Llega la transparencia” en Observatorio de Contratación Pública, 2015. Recuperado el 18 de noviembre de 2015 en: http://www.obcp.es/index.php/mod.opiniones/mem.detalle/id.216/relcategoria.121/relmenu.3/chk.432d $\underline{81119283 \mathrm{a} 4 \mathrm{~d} 5 \mathrm{~d} 1 \mathrm{~b} 8 \mathrm{f} 36 \mathrm{f} 34844888}$ 
Desde la perspectiva de la contratación pública, hay que añadir las previsiones específicas que recoge el TRLCSP ${ }^{117}$. En la fase de preparación de los contratos públicos, es esencial la publicidad de los anuncios de licitación para garantizar la igualdad en las condiciones de acceso.

Por un lado, se recoge en el art. 141 TRLCSP la posibilidad de llevar a cabo un anuncio previo de los contratos que se tenga previsto adjudicar en los doce meses siguientes a su publicación. Se publicarán en el Diario Oficial de la UE (DOUE) o en el perfil del contratante del órgano de contratación, lo cual a parte de ser de utilidad para dar a conocer futuras licitaciones, permite una reducción del plazo para su presentación.

Por otro lado, un requisito inexcusable de las licitaciones, tanto en procedimientos abiertos como en restringidos, será su publicación en el BOE, y en el DOUE si se tratan de contratos SARA, ante cuyo incumplimiento se considerarán nulos (art. 37.1 TRLCPS).

Asimismo, cabe añadir que la difusión de la documentación complementaria a los pliegos se hará por medios electrónicos o se enviará a los peticionarios antes de la finalización del plazo para presentar las ofertas (art. 158.1 TRLCSP). Con el fin de difundir la información señalada acerca de las licitaciones de los contratos públicos, está previsto que los órganos de contratación la incluyan en el perfil del contratante (art. 53 TRLCSP) y en la Plataforma de contratación del sector público (art. 334 TRLCSP).

Finalmente, en la fase de adjudicación es esencial la transparencia acerca de los motivos que hayan llevado a elegir a uno de los licitadores. Desde esta perspectiva, es necesario motivar de manera adecuada la elección, antes que nada, de los criterios de selección que se utilizarán para la adjudicación (art. 109.4 TRLCSP), que deberán indicarse, junto con su ponderación, en el anuncio de licitación, en el caso de que deban publicarse (art. 150.5 TRLCSP).

b) La publicidad de los contratos menores

Otro elemento que previene la arbitrariedad en la adjudicación es la obligación de su motivación, así como la necesidad de aportar la información al licitador excluido que permita conocer los motivos de tal decisión (art. 151.4 TRLCSP) ${ }^{118}$. Además, tras la

\footnotetext{
${ }_{117}$ Sin perjuicio de que las medidas que se comentan puedan ser de utilidad limitada en caso de que en el procedimiento de adjudicación se reduzca el nivel de competencia, como el negociado sin publicidad o en los contratos menores.

118 Según Blanco LóPEZ, los Tribunales de recursos especiales en materia de contratación están interpretando el art. 151 TRLCSP de tal manera que se garantice a los licitadores excluidos una verdadera justificación de los motivos por los que se toma esa decisión. En ese sentido, menciona la Resolución del TACRC núm. 947/2014, de 18 de diciembre, que en su pág. 10 señala que " puesto que
} 
formalización del contrato, se publicará en el perfil del contratante, salvo que se trate de un contrato menor o se justifique debidamente en el expediente (art. 153 TRLCSP).

Cabe señalar que el talón de Aquiles de la publicidad en la contratación pública son los contratos menores ${ }^{119}$. Esto es porque no se exige su formalización, basta con incorporar la factura al expediente (111 TRLCSP), por lo que esa falta de obligatoriedad restringe en gran medida el cumplimiento de los principios de libertad de acceso de los licitadores, publicidad y transparencia, ya que la adjudicación queda al albur del órgano de contratación (art. 138.3 TRLCSP).

Será necesario, en aplicación de la transparencia en este tipo de contratos, una resolución motivada que justifique su utilización por la necesidad de satisfacer de forma rápida aquellas actividades temporales de escasa cuantía ${ }^{120}$. En este tipo de contratos, pues, solo se podrá llevar a cabo un control ex post, puesto que no deja de ser de aplicación lo establecido en los arts. 4 y 8.1.a LTAIBG sobre la obligación de suministrar información. No obstante, no hay que confundir lo anterior con un fraccionamiento fraudulento del objeto del contrato en varios contratos menores con el fin de eludir las obligaciones de publicidad expuestas.

A este respecto, una forma habitual de eludir los principios de publicidad y transparencia de un contrato público es fraccionar indebidamente su objeto con la finalidad de que cada fracción de contrato no supere los umbrales mencionados y se califique formalmente como menor ${ }^{121}$. Esto lo prohíbe expresamente el art. 86.2

la ley exige que sea precisamente con la notificación del acuerdo de adjudicación como se haga llegar a los licitadores el conocimiento de las razones determinantes de la decisión adoptada,[...] sin que pueda exigirse de los licitadores una búsqueda de la información disponible para conocer las razones de la adjudicación" (BlAnCo LóPEZ, F. "Transparencia y motivación de la adjudicación" en Observatorio de Contratación Pública, 2015. Recuperado el 4 de octubre de 2015 en: http://www.obcp.es/index.php/mod.opiniones/mem.detalle/id.186/relcategoria.208/relmenu.3/chk.3f45 a8d43fbafae856ccde1e47f06a3d).

119 Tienen la consideración de contratos menores, según el art. 138.3 TRLCSP, “ los contratos de importe inferior a 50.000 euros, cuando se trate de contratos de obras, o a 18.000 euros" en el resto de casos. Además, deberán cumplir con el requisito del art. 23 TRLCSP de no tener una duración superior a un año ni posibilidad de prorrogarse.

120 BATET JiMÉNEZ, P. "Reflexiones sobre el fraccionamiento indebido de los contratos" en Observatorio de Contratación Pública, 2015. Recuperado el 12 de octubre de 2015 en: http://www.obcp.es/index.php/mod.opiniones/mem.detalle/id.204/chk.63802615ec54b48ac76c0a34e3e $\mathrm{d} 8804$

121 La JCCA del Estado dispuso en su informe 69/2008 que existirá fraccionamiento de contrato cuando "las diversas partes de la prestación que se contraten individualmente no sean susceptibles de aprovechamiento o utilización por separado por constituir una unidad funcional entre ellas, atendiendo a la finalidad que deben cumplir conjuntamente". Respecto del concepto jurídico indeterminado de "unidad funcional", la doctrina ha señalado que "habrá un único contrato cuando haya coincidencia en los elementos sujeto, objeto y causa, sin embargo, habrá que suscribir contratos diferentes cuando la ejecución adecuada de la prestación motive que uno de estos tres elementos varíe" (BATET JIMÉNEZ, P. "Reflexiones sobre el fraccionamiento indebido de los contratos" en Observatorio de Contratación Pública, 2015. Recuperado el 12 de octubre de 2015 en: http://www.obcp.es/index.php/mod.opiniones/mem.detalle/id.204/chk.63802615ec54b48ac76c0a34e3e 
TRLCSP, ya que se indica que la finalidad de los mismos es satisfacer de forma ágil las necesidades temporales de escasa cuantía de la administración, por lo que prima la simplificación procedimental a la libre concurrencia y transparencia. Por ello, en caso de uso fraudulento del contrato menor, se tendrá que declarar ilegal la contratación ${ }^{122}$.

c) Derecho de acceso a la información

Otra medida basada en la transparencia para evitar que se produzcan actos de corrupción es la posibilidad que se ofrece de acceder a la información relacionada con el sector público. Se trata de un derecho de cualquier persona a tener conocimiento sobre información relativa al sector público, facilitada por la administración, previa solicitud. Se recoge en el art. 105.b CE, y fue regulado en los arts. 35 y 37 LRJPAC.

Sin embargo, no se reconoce como derecho subjetivo hasta la promulgación de la LTAIBG, que contempla el derecho a acceder a la información pública en los arts. 12 y ss. Para ejercer el mismo no se requiere ostentar la posición de interesado ni demostrar ninguna relación con la información que se solicite. Es por ello que algunos autores utilizan el término de "transparencia pasiva" $" 23$.

En el ámbito de la contratación pública, este derecho tiene tres manifestaciones. En primer lugar, existe la posibilidad de que los interesados en una licitación soliciten acceder a los pliegos, a la documentación complementaria y a información adicional ${ }^{124}$ (art. 158.1 TRLCSP). Además, se incluye el acceso a la información relativa al contrato adjudicado, o incluso al expediente completo ${ }^{125}$. Ello permite que los no adjudicatarios puedan conocer mejor los motivos por los que no han sido seleccionados y tengan, en su caso, la oportunidad de interponer recurso ${ }^{126}$.

En segundo lugar, existe un Registro de contratos del sector público, dependiente

$\underline{\mathrm{d} 8804)}$.

122 Ibidem.

123 RazQuin Lizarraga, M. M. “Llega la transparencia” en Observatorio de Contratación Pública, 2015. Recuperado el 18 de noviembre de 2015 en: http://www.obcp.es/index.php/mod.opiniones/mem.detalle/id.216/relcategoria.121/relmenu.3/chk.432d 81119283a4d5d1b8f36f34844888

124 En el caso de que no se facilite la información pertinentemente solicitada al menos seis días antes de la fecha de finalización de recepción de ofertas, el plazo de presentación de las mismas se ampliará hasta que todos los interesados cuenten con la información de manera que puedan formular sus ofertas adecuadamente.

125 Esta posibilidad queda recogida en el art. 153 TRLCSP, sin perjuicio de que cierta información pueda ser calificada por los empresarios, respecto de sus propuestas, o por el órgano de contratación, respecto de la información que pueda perjudicar intereses generales o comerciales, como confidencial. Ello supone una gran barrera de acceso en numerosas ocasiones.

126 Cerrillo I Martínez, A. El Principio de Integridad en la Contratación Pública. Thomson Reuters, Pamplona, 2014, pág. 129. 
del Ministerio de Hacienda y Administraciones Públicas, en el que se inscriben, como apunta el art. 333 TRLCSP, los "datos básicos de los contratos adjudicados por las distintas administraciones públicas y demás entidades del sector público", así como "sus modificaciones, prórrogas, variaciones de plazos o precio, su importe final y extinción”. Los órganos de contratación de todas las entidades contenidas en el ámbito de aplicación del TRLCSP remitirán al Registro los datos señalados, con lo que se configura un sistema oficial centralizado de acceso público sobre la contratación pública en España.

Constituye "una base de datos que abarca toda la vida del contrato y en la que se consolida la información de todo el sector público" ${ }^{127}$. Se trata, por tanto, de un soporte para el conocimiento, difusión y acceso a la información de la contratación pública, de conformidad con el principio de transparencia.

En tercer lugar, se encuentra el Registro oficial de licitadores y empresas clasificadas del Estado. De inscripción voluntaria, recoge información sobre diferentes empresas $^{128}$. Existe uno dependiente del Ministerio de Hacienda (art. 326 TRLCSP), pero cabe la posibilidad de que las Comunidades Autónomas creen otros (art. 327 TRLCSP). Se trata de un Registro de carácter público, por lo que los solicitantes no tienen que mostrar ningún interés directo o indirecto en relación con el contrato del que precisen información.

\subsubsection{Profesionalización y neutralidad de la Mesa de contratación}

Un factor clave para promover la integridad en la contratación pública, y por lo tanto evitar que se produzcan actos de corrupción, pasa por la profesionalización del sector de la contratación pública mediante una mejor formación. Este fue uno de los objetivos recogidos en la conclusión sexta de la Declaración de Cracovia ${ }^{129}$. Se trata de lograr una mayor formación y responsabilidad de los gestores públicos y evitar un exceso de politización de los órganos de contratación ${ }^{130}$.

127 Sanmartín Mora, M. A. "El Registro de Contratos del Sector Público como herramienta para el cumplimiento de las obligaciones de transparencia" en Observatorio de Contratación Pública, 2015. Recuperado el 14 de noviembre de 2015 en: http://www.obcp.es/index.php/mod.opiniones/mem.detalle/id.200/relcategoria.208/relmenu.3/chk.e3e4 b60f68edba6e80ff8130537705e7

128 El art. 328 TRLCSP incluye datos relativos a la personalidad y capacidad de obrar de las empresas, la extensión de las facultades de los representantes o apoderados, autorizaciones o habilitaciones profesionales y datos relativos a la solvencia económica y financiera, entre otros.

129 Es un documento que recoge las conclusiones sobre medidas para mejorar el funcionamiento de la legislación comunitaria del primer Foro del Mercado Interior que se celebró en dicha ciudad durante los días 3 y 4 de octubre de 2011.

130 Gimeno Feliu, J. M. "Reforma de la normativa europea sobre contratación administrativa y transparencia en la contratación por parte del sector público" en Seminario sobre Transparencia administrativa y protección de los intereses financieros de la Unión Europea en la Eurorregión 
En ese sentido, la buena gestión constituye un pilar de la integridad, y "consiste en hacer frente a las deficiencias comunes en la planificación y gestión de la contratación pública e incluir las necesidades que no están bien valoradas, mejorar los presupuestos poco realistas o formar funcionarios que están poco cualificados"131.

Por ello, es importante facilitar formación y potenciar las capacidades profesionales sobre contratación pública e integridad a los responsables de la contratación, y en especial a los que forman la Mesa de contratación ${ }^{132}$, por su singular papel en el procedimiento ${ }^{133}$. Esto podría fomentar su capacidad de moderación en las situaciones en que se produzca algún conflicto de intereses, equilibrándolas y atendiendo a la satisfacción del interés general, lo cual elevaría la neutralidad en la toma de decisiones ${ }^{134}$.

Hay que tener presente que el art. 26 LTAIBG recoge una serie de principios de buen gobierno que deberán ser seguidos por las entidades del sector público estatal y los organismos adscritos a él, tales como la imparcialidad, mantenimiento de un criterio independiente al interés particular, la diligencia debida en el cumplimiento de sus obligaciones o el pleno respeto a la normativa reguladora de los conflictos de intereses. Ello es un recurso que sirve, sin duda, para mejorar la toma de decisiones a la hora de establecer un contrato público, pero no es suficiente.

El legislador debe ir más allá y establecer una capacitación suficiente a los titulares de los órganos de contratación y el personal de apoyo, incluida la Mesa de contratación, a la hora de adjudicar un contrato público. En relación con el perfil político o técnico de los órganos de contratación, no son pocos los estudios que se han llevado a cabo sobre el impacto positivo contra la corrupción que tendría la mayor atribución de capacidad decisoria a los perfiles técnicos de cada administración pública.

Mediante la atribución de la competencia de adjudicación de contratos públicos a una Mesa de contratación formada por miembros especialistas en la materia, se lograría una mayor precisión técnica a la hora de adjudicar los contratos, además de una

Galicia-Norte de Portugal, 2014, pág. 3. Recuperado el 15 de octubre de 2015 en: http://egap.xunta.es/recursos/pdf/[1 1399371138]03.pdf

131 Cerrillo I Martínez, A. El Principio de Integridad en la Contratación Pública. Thomson Reuters, Pamplona, 2014, pág. 66.

${ }^{132}$ Se trata de un órgano colegiado compuesto por un presidente, un secretario y varios vocales, designados por el órgano de contratación. Le corresponde garantizar el buen desarrollo del procedimiento de licitación, valorar las ofertas y seleccionar la oferta económicamente más ventajosa para el órgano de contratación. Se regula en los arts. 320 y ss. TRLCSP.

133 OCDE. "Principles for Integrity in Public procurement", París, 2009, principio 4. Recuperado el 1 de octubre de 2015 en: http://www.oecd.org/gov/ethics/48994520.pdf

${ }^{134}$ Cerrillo i Martínez, A. El Principio de Integridad en la Contratación Pública. Thomson Reuters, Pamplona, 2014, pág. 162. 
minimización del riesgo de establecer relaciones clientelares o adjudicaciones fraudulentas ${ }^{135}$.

Asimismo, es capital incluir y reforzar la presencia de funcionarios profesionales en los órganos decisorios de la selección de contratistas, puesto que la "atribución en exclusiva a cargos políticos de las competencias contractuales, con escasa participación técnica, incrementa en todo caso los riesgos de corrupción, mientras que dejar estas decisiones sobre todo en manos de funcionarios debidamente controlados, integrados en órganos colegiados, aminora los peligros de distorsión de los procesos" ${ }^{136}$.

Finalmente, señalar que existen una serie de autores, entre los que destaca Cantera Cuartango, que defienden que la Mesa de contratación debería cobrar presencia en la ejecución del contrato ${ }^{137}$. Dado que se trata del órgano que evalúa la oferta adecuada, debería ser ella la que controlara la ejecución del contrato, su adecuación a la legalidad y la fidelidad al programa presupuestario fijado previamente en la adjudicación.

Esta medida, señala el autor, supondría un gran avance en la integridad dentro de la contratación pública, puesto que serviría como medio de control para evitar, por ejemplo, la modificación sustancial de los contratos que altere lo previsto en la adjudicación y que supone, generalmente, un incremento de la dotación pública.

\subsubsection{Limitación del ius variandi ${ }^{138}$}

El uso inadecuado de la prerrogativa del ius variandi ${ }^{139}$ por parte de las administraciones públicas ha generado en España un elevado número de disfuncionalidades en la contratación pública. Así lo certifica el Informe de la comisión

${ }^{135}$ Gimeno Feliu, J. M. "La reforma comunitaria en materia de contratos públicos y su incidencia en la legislación española. Una visión desde la perspectiva de la integridad" en Congreso AEPDA, 2015, pág. 45. Recuperado el 5 de octubre de 2015 en: http://www.csital.org/sites/default/files/Pon\%C3\%A8ncia\%20Jos\%C3\%A9\%20Mar\%C3\%ADa \%20Gimeno.pdf

136 RIVERO ORTEGA, R. "Derecho administrativo, reformas de segunda generación, desarrollo y control de la corrupción" en XVIII Concurso de Ensayos del CLAD sobre Reforma del Estado y Modernización de la Administración Pública, 2014, pág. 31. Recuperado el 24 de octubre de 2015 en: http://siare.clad.org/fulltext/0052007.pdf

137 Cantera Cuartango, J. M. "La Mesa de Contratación: un instrumento de control financiero, del gasto público y de legalidad en tiempos de crisis económica" en Auditoría Pública, núm. 58, 2012, págs. 51 -60 .

${ }^{138}$ Para un análisis más exhaustivo sobre el concepto de ius variandi, vide VÁzquez Matilla, F. J. La modificación de los contratos públicos. Thomson Reuters, Cizur Menor (Navarra), 2015.

139 Concepto definido por Santamaría Pastor como "facultad de la administración contratante de imponer al contratista modificaciones del objeto del contrato cuando sea necesario por razones sobrevenidas" (Santamaría Pastor, J. A. Principios de Derecho Administrativo General. Volumen II. Iustel, Madrid, 2015, pág. 242). 
de expertos del Ministerio de Hacienda cuando señala que las modificaciones contractuales pueden desvirtuar el principio de competencia y no discriminación reflejado en la adjudicación, ya que el precio por el que se ejecuta finalmente un contrato no es aquel por el que licitó, sin perjuicio de que ello pueda generar prácticas corruptas en el caso de que se intente compensar una oferta que había pujado excesivamente a la baja ${ }^{140}$.

En una primera etapa, la normativa europea preveía un riguroso respeto de los principios de igualdad de trato y transparencia exclusivamente en la fase de elección del adjudicatario. Tuvo que tomar partido el TJUE para corregir aquellas conductas que distorsionaban el mercado interior en la fase de ejecución, en tanto que se favorecía a un competidor frente al resto en aplicación, generalmente, del ius variandi.

Se puede indicar la STJUE de 29 de abril de $2004^{141}$, la cual señaló a este respecto que la modificación de un contrato que afecta a las condiciones esenciales de la licitación produciría "la vulneración de los principios de transparencia e igualdad de trato entre los licitadores, puesto que la aplicación uniforme de las condiciones de licitación y la objetividad del procedimiento dejarían de estar garantizadas”.

Asimismo, añadió que "la entidad adjudicadora tampoco está autorizada a alterar el sistema general de la licitación modificando unilateralmente más tarde una de sus condiciones esenciales $^{142} \mathrm{y}$, en particular, una estipulación que, si hubiese figurado en el anuncio de licitación, habría permitido a los licitadores presentar ofertas sustancialmente diferentes".

En el mismo sentido se pronuncia VázQuez Matilla, al señalar que "[s]e debe evitar que existan cambios significativos en los contratos, ya que en estos casos el resto de licitadores pudo presentar una oferta radicalmente distinta pero sobre todo porque está en juego la integridad y la eficiencia del contrato" ${ }^{143}$. Así, al modificar el contenido del contrato, se desnaturaliza la exigencia de los criterios de solvencia establecidos

${ }^{140}$ Ministerio DE HACIENDA. "Informe y conclusiones de la comisión de expertos para el estudio y diagnóstico de la situación de la contratación pública”, 2014, pág. 118. Recuperado el 2 de noviembre de 2015 en:

http://www.minhap.gob.es/Documentacion/Publico/Subsecretaria/Gabinete\%20Tecnico/libro $\% 20$ contratacion.pdf

141 STJUE de 29 de abril de 2004, asunto Succhi di Frutta (TJCE 2004/125).

${ }^{142}$ Para un análisis más exhaustivo sobre el concepto de condiciones sustanciales del contrato público vide GAllego CórColes, I. "La modificación de los contratos en la cuarta generación de directivas sobre contratación pública" en Congreso AEPDA, 2014, págs. 8 - 20.

143 VÁzquez Matilla, F. J. "La corrupción una barrera a la eficiencia e integridad en la compra pública" en Observatorio de Contratación Pública, 2012. Recuperado el 3 de noviembre de 2015 en: http://www.obcp.es/index.php/mod.opiniones/mem.detalle/id.80/relcategoria.121/relmenu.3/chk.19744 9cc92600ed0a6d22b3a98431ebd 
inicialmente en los pliegos para la adjudicación. En tal caso, se hubieran debido exigir otros requisitos relacionados con el nuevo objeto del contrato para la selección del licitador óptimo.

Como regla general, la administración está sujeta al principio de invariabilidad o inmutabilidad de los contratos públicos que suscribe, según la regla de pacta sunt servanda ${ }^{144}$. Por lo tanto, cualquier modificación sustancial de los elementos objetivos de un contrato público por parte de la administración mientras se encuentra vigente, precisa de una nueva adjudicación. Esta circunstancia no pretende proteger al contratista, sino a los licitadores, ya que de otro modo no se respetaría el principio de libre concurrencia ${ }^{145}$.

Esta regla general la recoge tanto el art. 105 TRLCSP como el art. 72 de la Directiva 2014/24/UE y el art. 43 de la Directiva 2014/23/UE. No obstante, se establecen una serie de supuestos tasados que permiten modificar un contrato en fase de ejecución sin necesidad de establecer un nuevo proceso de adjudicación.

En primer lugar, cuando esté previsto en los pliegos o en el anuncio de licitación de manera clara y expresa (art. 106 TRLCSP). En ellos se deberá detallar las condiciones objetivas que permitan la modificación, su alcance y límites (con indicación del porcentaje del precio que puede afectar como máximo) y el procedimiento que se tiene que seguir. Este motivo lo recoge la directiva 2014/24/UE, que añade la necesidad de que las cláusulas sean claras, precisas e inequívocas.

En segundo lugar, por errores u omisiones de la redacción del proyecto o las redacciones técnicas (art. 107.1.a TRLCSP). Este supuesto no se recoge ni en la directiva 2014/24/UE ni en el Anteproyecto LCSP, por lo que su pervivencia en el ordenamiento español será limitada.

En tercer lugar, cuando el caso fortuito o la fuerza mayor hiciesen imposible la realización técnica (art. 107.1.c TRLCSP) o cuando, por circunstancias naturales conocidas con posterioridad a la adjudicación no previsibles, devenga inadecuado el proyecto (art. 107.1.b TRLCSP). La Directiva 2014/24/UE señala esta circunstancia en el art. 72.1.c, pero con mayores limitaciones respecto de la alteración de la naturaleza del contrato y del precio que se incluyen en el art. 203.2.b del Anteproyecto LCSP.

En cuarto lugar, cuando sea conveniente incorporar a la prestación avances

\footnotetext{
144 VÁzQuez Matilla, F. J. La modificación de los contratos públicos. Thomson Reuters, Cizur Menor (Navarra), 2015, pág. 30.

145 GAllego CóRCOLES, I. "La modificación de los contratos en la cuarta generación de directivas sobre contratación pública” en Congreso AEPDA, 2014, pág. 56.
} 
técnicos conocidos tras la ejecución del contrato que la mejores notoriamente. Al igual que el supuesto del art. 107.1.a TRLCSP, este está condenado a desaparecer puesto que no se recoge en ninguno de los dos cuerpos normativos citados.

Finalmente, señalar dos cuestiones. Por una parte, que en ninguno de los motivos mencionados, salvo en el primero, podrá producirse una alteración de las condiciones esenciales de la licitación y adjudicación. La necesaria previsión de que figure en los pliegos iniciales no genera inseguridad ni un desequilibrio entre los licitadores no adjudicatarios, puesto que lo pudieron prever a la hora de presentar sus ofertas (art. 107.2 TRLCSP).

Por otra parte, la Directiva 2014/24/UE incluye en su art. 72.1 in fine la obligación de publicar, en tanto elemento de control y en cumplimiento de las exigencias de transparencia, las decisiones de modificaciones contractuales ${ }^{146}$. El acceso a dicha información facilita una eventual impugnación por quienes tuvieran legitimación, para el caso que se hubieran sobrepasado los límites legales del ius variandi ${ }^{147}$.

En este sentido, VÁZquez MATILla señala que la regulación debería ir un paso más allá. Debería permitir a "cualquier persona" recurrir modificaciones contractuales que se excedan de lo permitido por la ley, en tanto que en calidad de "contribuyente" debería poder evitar que se corrompa la gestión económica de los recursos públicos por esta vía ${ }^{148}$.

\subsubsection{Colusión empresarial en el proceso de licitación}

La ausencia de competencia real en la fase de licitación no siempre está ligada a una conducta irregular de la administración, sino que también puede ser consecuencia de pactos colusorios entre los licitadores. Cuando estos se ponen de acuerdo en cualquier condición comercial, especialmente el precio o el reparto de cuota de mercado, frustran el principio de libertad de concurrencia y la eficiencia de la gestión administrativa respecto de la oferta económicamente más ventajosa ${ }^{149}$. Como señala LóPEZ MiÑo, "las infracciones son cometidas por los candidatos puertas afuera del procedimiento de

\footnotetext{
146 Ello se recoge actualmente en el art. 8.1.a LTAIBG.

147 No obstante, la sentencia supra mencionada (STJUE de 29 de abril de 2004, asunto Succhi di Frutta) admite la legitimación de un licitador no adjudicatario en un recurso frente a una modificación.

148 VÁzQUez Matilla, J. F. "La corrupción una barrera a la eficiencia e integridad en la compra pública" en Observatorio de Contratación Pública, 2012. Recuperado el 3 de noviembre de 2015 en: http://www.obcp.es/index.php/mod.opiniones/mem.detalle/id.80/relcategoria.121/relmenu.3/chk.19744 9cc92600ed0a6d22b3a98431ebd

149 Cerrillo I Martínez, A. El Principio de Integridad en la Contratación Pública. Thomson Reuters, Pamplona, 2014, pág. 159.
} 
contratación, pero operan y producen efectos en el mismo" ${ }^{150}$.

La colusión entre empresas supone una conducta proscrita por el Derecho de la competencia $^{151}$, pero a pesar de su carácter transversal, no logra enteramente sus objetivos en la contratación pública. La acción para acotar estas prácticas corresponde a la autoridades de la competencia, en concreto a la CNMC, que está facultada para ejercitar su función de inspección e incluso iniciar un procedimiento administrativo sancionador contra los licitadores que constriñan la competencia ${ }^{152}$.

Sin embargo, el TRLCSP no reconoce la capacidad de la CNMC para oponerse en el procedimiento de contratación, por lo que deberá acudir a la jurisdicción contencioso-administrativa para "impugnar actos de los que se deriven obstáculos al mantenimiento de una competencia efectiva" ${ }^{" 153}$. De esta falta de medios para combatir la colusión en la contratación pública también se ha hecho eco la propia CNMC.

En su último informe sobre la contratación pública en España ${ }^{154}$ ha recalcado la necesidad de establecer mecanismos de coordinación entre la CNMC y los organismos de contratación pública. Propone, entre otras cuestiones, desarrollar programas para aumentar el conocimiento del papel de la CNMC en temas de contratación pública, o la redacción "procompetitiva" de los pliegos.

Una medida introducida por la Directiva 2014/24/UE que permite ampliar la base de licitadores, y por tanto, fortalecer la competencia, es la división generalizada de los contratos públicos en lotes. El art. 46 de dicha norma invierte la regla general aplicada hasta ahora, de tal manera que habrá que justificar la no división del contrato, pudiendo limitar el número de lotes al que puede acceder cada licitador. Esto se incluye en el art. 99 Anteproyecto LCSP.

La consecuencia inmediata de esta medida es la posibilidad de que un mayor número de empresas de menor tamaño puedan acceder, con posibilidades reales de ser seleccionadas, a los procesos de licitación de contratos públicos. De otro modo, las empresas de mayor tamaño, dominantes en el mercado, son más proclives a copar la mayoría de adjudicaciones, puesto que cuentan con más recursos y solvencia.

\footnotetext{
${ }^{150}$ LÓPEZ MiÑo, A. "Insuficiencia del derecho español para impedir y corregir la colusión en la contratación pública" en Proyecto de investigación "Contratación pública y transparencia: alcance y límites de los principios de publicidad y libre competencia”, 2012.

151 Art. 1 Ley 15/2007, de 3 de julio, de defensa de la competencia.

152 Art. 61 Ley 15/2007, de 3 de julio, de defensa de la competencia.

153 Art. 12.3 Ley 15/2007, de 3 de julio, de defensa de la competencia.

${ }^{154}$ CNMC. "Análisis de la contratación pública en España: oportunidades de mejora desde el punto de vista de la competencia”, 2015. Recuperado el 1 de octubre de 2015 en: http://www.cnmc.es/Portals/0/Notas\%20de\%20prensa/201502_Informe_ContratacionPublica.pdf
} 
Ello tiene un efecto directo en la competencia, puesto que cuantos más agentes económicos participen, más posibilidades existen de que la oferta económicamente más ventajosa sea competitiva. En consecuencia, se limita la capacidad de colusión de los operadores económicos. Además, con esta medida se promueve uno de los objetivos de la "estrategia europea de contratación 2020", como es el fomento de las PYME, pieza clave del tejido empresarial y del sector industrial europeo.

\subsection{Medidas posteriores a la adjudicación del contrato}

\subsubsection{Rendición de cuentas}

Como se ha mencionado supra, la transparencia es un principio que favorece la concurrencia y promueve condiciones de igualdad entre los licitadores para competir en el proceso de selección. Sin embargo, la transparencia también sirve a la finalidad de rendir cuentas a la sociedad sobre la actuación administrativa. Es necesario un marco legal que permita la creación de herramientas que faciliten el conocimiento de la gestión pública, es decir, qué, cómo y cuántos recursos públicos se invierten mediante la contratación pública. Un control político y público de la actuación administrativa, sin duda, legitima su posición ${ }^{155}$.

Una medida que se ha tomado recientemente en el ámbito de la transparencia y publicidad es la creación de mecanismos electrónicos de difusión de información que clarifican y facilitan que se lleve a cabo un mejor conocimiento de las actividades de la administración pública. Dos son las vías que se van a señalar por las que se transmite información relativa a la contratación pública, facilitando su fiscalización.

a) Plataforma de contratación del sector público

Consiste en una "ventanilla única electrónica" que reconduce de manera ágil y accesible la información de los perfiles del contratante. Se trata, en definitiva, de enmendar eficazmente la confusión creada mediante la fragmentación del modelo de publicidad que existía previamente.

El sistema de publicidad anterior permitía que todo ente contratante creara su propio perfil del contratante, surgiendo miles de ellos, lo que fragmentó el acceso a la información y generó cierta inseguridad jurídica ${ }^{156}$. Ello se intentó corregir

155 Gimeno Feliu, J. M. "Decálogo de reglas para prevenir la corrupción en los contratos públicos" en Observatorio de Contratación Pública, 2014. Recuperado el 15 de septiembre de 2015 en:

http://www.obcp.es/index.php/mod.opiniones/mem.detalle/id.180/relcategoria.208/relmenu.3/chk.1b2c 9f6d99eecf44223c17ac60720747

156 Gimeno Feliu, J. M. "La obligación de publicidad de todas las licitaciones en la plataforma de 
introduciendo, mediante el art. 334 TRLCSP, una Plataforma de contratación del Estado que aglutinara los perfiles del contratante de los órganos de contratación del sector público de estatal.

Pero no fue hasta que la Disposición adicional tercera de la Ley 20/2013, de 9 de diciembre, de garantía de unidad de mercado, cambió su nombre por el de Plataforma del sector público y permitió la interconexión de la información de las diferentes administraciones y entidades públicas, así como la convocatoria de licitaciones y sus resultados respecto de todas las entidades comprendidas en el ámbito subjetivo del TRLCSP.

La actualización de la información en dicha Plataforma no es una mera formalidad, puesto que la no publicación en ella de la convocatoria de licitaciones tendrá consecuencias jurídicas, como el retraso de la fecha límite para presentar solicitudes de participación. Asimismo, la inobservancia de dicho precepto comportaría una infracción jurídica que puede implicar un vicio de invalidez ${ }^{157}$.

En definitiva, se trata de un elemento esencial para que cualquier operador económico o jurídico conozca el objeto de las diferentes licitaciones ofertadas por el sector público y que valore si alguna es de su interés.

b) Portal de la transparencia

Regulado en el art. 10 LTAIBG y dependiente del Ministerio de Presidencia, supone un mecanismo electrónico que facilita el acceso de los ciudadanos a la información a la que se refiere la propia ley, incluyendo la relativa a los contratos públicos.

Incorpora información de cada contrato de cada Ministerio relativa al objeto, la duración, el importe de licitación y adjudicación, el tipo de procedimiento que se ha utilizado, los diferentes instrumentos de publicidad que se han empleado y el número de participantes en el procedimiento, así como las posibles modificaciones posteriores del contrato o las decisiones de desistimiento o renuncia ${ }^{158}$.

Indica el art. 9.3 LTAIBG que el "incumplimiento reiterado de las obligaciones

contratos del sector público" en Observatorio de Contratación Pública, 2014. Recuperado el 2 de octubre de 2015 en:

http://www.obcp.es/index.php/mod.opiniones/mem.detalle/id.153/relcategoria.121/relmenu.3/chk.577429fa 7149b11b2d930ebe5b579d9f

157 Ibidem.

158 Portal de la Transparencia. "Contratos, convenios y subvenciones", 2015. Recuperado el 25 de octubre de 2015 en:

http://transparencia.gob.es/transparencia/transparencia_Home/index/categorias/Contratos-convenios$\underline{\text { subvenciones/Contratos.html }}$ 
de publicidad activa reguladas en este capítulo tendrá la consideración de infracción grave", por lo que lo recogido en la norma respecto de la transparencia no tiene la consideración de mero formalismo, y su conculcación acarrea consecuencias jurídicas.

\subsubsection{Recuperación de los bienes defraudados}

La Disposición final primera de la Ley Orgánica 5/2010, de 22 de junio, por la que se modifica la Ley Orgánica 10/1995, de 23 de noviembre, del Código Penal, añadió el art. 367 septies a la LECrim, el cual contempló la creación de una Oficina de Recuperación de Activos. Transcurridos cinco años, esa previsión se desarrolló mediante el Real Decreto 948/2015, de 23 de octubre, por el que se regula la Oficina de Recuperación y Gestión de Activos, que depende del Ministerio de Justicia.

La creación de este órgano coadyuva a combatir la impunidad de los actos de corrupción. A pesar de que está concebido como mecanismo para recuperar las ganancias derivadas de cualquier delito económico ${ }^{159}$, incluye entre ellos los numerosos casos de corrupción en el sector público, en los que son susceptibles de estar inmersos los cargos o funcionarios públicos.

La intervención de la ORGA supone un elemento esencial en la materia del decomiso, tanto el provisional como el definitivo ${ }^{160}$. Se trata de un organismo multidisciplinar encargado de localizar los bienes y ganancias vinculados con actividades delictivas, con el fin de gestionarlos de manera eficiente para su posterior adjudicación o, en su caso realización.

En el momento en que reciba la resolución judicial o el decreto del fiscal que inste su intervención, la ORGA podrá llevar a cabo las actuaciones de investigación patrimonial que procedan para localizar y recuperar los bienes del investigado o encausado. Una vez recuperados, se encargará de su conservación y administración, pudiendo proceder, previa autorización judicial, a la realización anticipada o utilización provisional de los bienes intervenidos ${ }^{161}$.

Se recoge una lista de personas jurídicas que podrán ser beneficiarias de los recursos obtenidos mediante las gestiones de la ORGA, como la propia ORGA o la Administración General del Estado (para que promueva los fines de la norma de creación de la ORGA ), organizaciones no gubernamentales, oficinas de asistencia a las

\footnotetext{
159 Función atribuida a la ORGA en el art. 3.1 RD 948/2015, de 23 de octubre.

160 Es un presupuesto básico para el funcionamiento de la ORGA una adecuada regulación de la figura del decomiso, la cual se ha visto reforzada mediante la Ley Orgánica 1/2015, de 30 de marzo, por la que se modifica la Ley Orgánica 10/1995, de 23 de noviembre, del Código Penal.

161 Art. 11 RD 948/2015, de 23 de octubre.
} 
víctimas o la Agencia Estatal de Administración Tributaria, entre otras.

Se trata, por tanto, de evitar algo tan criticado por la opinión pública como que una persona condenada por un delito, incluidos los de corrupción, a la que que le haya generado enriquecimiento injusto, pueda cumplir la pena que le corresponda pero preservando el patrimonio obtenido mediante la actividad ilícita por la que es condenada $^{162}$.

Ello, asimismo, encaja dentro del marco de transparencia que hemos estudiado supra, con el fin de combatir la corrupción, "haciendo realidad el principio de que el delito que genera ilícitas ganancias nunca debe compensar a su autor"163. Esta consecuencia suponer una carga más para una persona inmersa en una investigación de un acto de corrupción pública, lo cual sin duda supone una fuerte barrera disuasoria a la hora de decantar una situación de conflicto de interés hacia un acto de corrupción.

\subsubsection{Organismos de control y fiscalización}

Es necesaria la existencia de instituciones que sirvan para controlar la actuación de la administración en relación con la contratación pública. Por ello es esencial contar con organismos y medidas que permitan llevar a cabo un seguimiento de las actividades administrativas para una pronta detección ineficacias, conflictos e ilegalidades ${ }^{164}$.

Así, el ordenamiento jurídico español cuenta con varios organismos cuyo fin es detectar posibles irregularidades en este ámbito, incluidos los actos de corrupción, sin perjuicio de las jurisdicciones contencioso-administrativa y la penal. A continuación se describen cinco instituciones que sirven a ese fin.

a) Tribunal de Cuentas

Constituye "el supremo órgano fiscalizador de las cuentas y de la gestión económica del Estado en el sector público" (art. 1 LOTCu). Se trata de un órgano dotado de independencia y comisionado por las Cortes Generales, cuya actuación se extiende a todo el sector público ${ }^{165}$.

Por una parte, ejerce una función de enjuiciamiento contable, recopilando en informes y memorias que incluyen cuantas infracciones, prácticas irregulares y

\footnotetext{
${ }^{162}$ JAÉN VALLEJo, M. "Recuperación de activos derivados del delito: un objetivo prioritario de la reforma penal" en Diario La Ley, núm. 8545, 2015.

163 Ibidem.

164 Cerrillo I Martínez, A. El Principio de Integridad en la Contratación Pública. Thomson Reuters, Pamplona, 2014, pág. 258.

165 Ibidem, pág. 285.
} 
recomendaciones encuentra. Todo ello permite depurar las responsabilidades contables que concurren en los casos en que, por acción u omisión contraria a la ley, se origina un menoscabo de los caudales públicos, subsistiendo la obligación de indemnización de los daños y perjuicios causados (art. 38 LOTCu). Asimismo, el art. 72 LOTCu permite juzgar la malversación que se considere ilícito contable, lo cual supone uno de los hechos más habituales de corrupción ${ }^{166}$.

Por otra parte, el Tribunal de Cuentas ejerce una función fiscalizadora de carácter externo referida al sometimiento de la actividad financiera a los principios de legalidad, eficiencia y economía. Concretamente, fiscaliza los contratos celebrados por el sector público en sus distintas fases, desde la preparación, la adjudicación, la formalización, la ejecución o una eventual modificación. No obstante, se dan dos limitaciones a este respecto que merman en gran medida su efectividad.

Así, no se prevé que todos los contratos sean objeto de supervisión, sino únicamente aquellos que superen una determinada cantidad económica o los que, teniendo un importe de más de sesenta mil euros, hubieran sido objeto de modificación que suponga un incremento del gasto de al menos un 20\% (art. 39 LOTCu). Además, no lleva a cabo investigaciones sobre las irregularidades que analiza ${ }^{167}$, más allá de elevarlas a las Cortes Generales y publicarse en el $\mathrm{BOE}^{168}$.

\section{b) Inspecciones Generales de Servicios}

Son órganos especializados de cada Ministerio que los controla y evalúa de manera interna, así como a sus órganos dependientes. Se regulan mediante el Real Decreto $799 / 2005^{169}$. No intervienen directamente en el proceso de contratación, pero su actividad fomenta la vigencia del principio de integridad en la contratación pública.

A la luz del art. 2 de la norma mencionada, entre sus funciones más destacadas se encuentran "examinar actuaciones presuntamente irregulares de los empleados públicos en el ejercicio de su cargo, promover actuaciones que favorezcan la integridad profesional y comportamientos éticos o inspeccionar y supervisar la actuación y el

\footnotetext{
166 Ibidem, pág. 288.

167 Dentro de las actividades que investiga el Tribunal de Cuentas se encuentran el fraccionamiento de los contratos con el fin de adjudicarlos utilizando mecanismos de publicidad menos exigentes, la contratación de asistencia técnica cuando la administración ya contaba con los medios necesarios o la no aplicación de penalizaciones acordadas por incumplimiento del contratista, entre otras. (CERRILLO I Martínez, A. El Principio de Integridad en la Contratación Pública. Thomson Reuters, Pamplona, 2014, pág. 288)

168 Cerrillo I Martínez, A. El Principio de Integridad en la Contratación Pública. Thomson Reuters, Pamplona, 2014, pág. 287.

169 Real Decreto 799/2005, de 1 de julio, por el que se regulan las inspecciones generales de servicios de los departamentos ministeriales.
} 
funcionamiento de las unidades, órganos y organismos del departamento".

El art. 12 indica que las Inspecciones generales gozan de "independencia respecto a los órganos y personas objeto de inspección”, aunque hay que tener en cuenta el efecto que en este sentido puede generar la dependencia orgánica de un Ministerio. No obstante, según apunta el art. 13, deberán recibir cuanta información consideren necesaria para el desarrollo de su actividad de las autoridades pertinentes.

Su eficacia radica en mayor medida en el análisis de las situaciones irregulares y de la compatibilidad de la actividad de los empleados públicos, ya que no dispone de capacidad decisoria más allá de proponer a los órganos competentes las medidas oportunas para garantizar la integridad ${ }^{170}$.

c) Oficina de Conflictos de Intereses

Se trata de un órgano adscrito al Ministerio de Hacienda y Administraciones Públicas competente para supervisar el cumplimiento de las incompatibilidades y obligaciones recogidas en las normas relativas a la prevención de conflictos de intereses, en especial, el Estatuto del alto cargo.

En relación con su capacidad de control, su principal función es recopilar información y gestionar el régimen de incompatibilidades de los altos cargos y empleados públicos, con el fin de asegurar el cumplimiento de las obligaciones del Estatuto del alto cargo (art. 19).

En el ámbito sancionador, instruye expedientes sancionadores respecto de conductas que puedan vulnerar el régimen de conflictos de intereses o recibe las denuncias que se formulen sobre presuntos incumplimientos (art. 27).

\section{d) Consejo de Transparencia y Buen Gobierno}

Es un órgano creado por la LTAIBG cuyo objetivo, según su art. 34, es promover la transparencia y garantizar el buen gobierno. Está formado por la Comisión de la transparencia y buen gobierno, la cual cuenta con personas de diferentes instituciones públicas $^{171}$, y un Presidente, nombrado mediante Real Decreto a propuesta del Ministro de Hacienda y Administraciones Públicas ${ }^{172}$.

Su función principal es proteger y favorecer el ejercicio del derecho de acceso a la información pública mediante un proceso ágil. Ello sirve de apoyo para que se pueda

\footnotetext{
${ }^{170}$ Cerrillo I Martínez, A. El Principio de Integridad en la Contratación Pública. Thomson Reuters, Pamplona, 2014, pág. 263.

171 El art. 36 LTAIBG establece que estará formado por un senador, un diputado, un representante del Tribunal de Cuentas y el Defensor del Pueblo, entre otros.

172 Art. 37 LTAIBG.
} 
llevar a cabo una función de fiscalización y control en todo momento del cumplimiento de lo establecido en la LTAIBG, que incluye, como se ha analizado supra, el ámbito de la contratación pública.

No obstante, el art. 38 le atribuye otras funciones, como recomendar y promover normas de desarrollo y buenas práctica en materia de transparencia, instar el inicio del procedimiento sancionador respecto de las conductas previstas en la LTAIBG o elaborar una memoria anual sobre el desarrollo de sus funciones y el grado de cumplimiento de la LTAIBG que se remitirá al Congreso de los Diputados, entre otras. Asimismo, se prevé su colaboración con órganos autonómicos análogos.

e) Junta Consultiva de Contratación Administrativa

La Directiva 2014/24/UE señala en su art. 83 que los Estados velarán por el cumplimiento de las normas de contratación pública, que será llevada a cabo por autoridades, organismos o estructuras de supervisión que cuenten con medios y preparación suficientes. Además, deberán presentar un informe cada tres años a la Comisión Europea sobre "posibles problemas estructurales o recurrentes en la aplicación de la legislación de contratación pública o sobre la prevención, detección y notificación adecuada de los casos de fraude, corrupción, conflicto de intereses y otras irregularidades graves en la contratación".

Esta parte ha sido incluida con bastante literalidad en el art. 326 del Anteproyecto LCSP, haciendo recaer este nuevo rol sobre la JCCA del Estado, y por medio de la cooperación, en las Juntas Consultivas de Contratación de las Comunidades Autónomas. 


\section{CONCLUSIONES}

1. La actual percepción generalizada de corrupción en España está influenciada por los numerosos casos que han salido a la luz pública recientemente. La difusión de los mismos en un momento de profunda crisis económica ha extendido la impresión de que es una práctica común. Sin embargo, los datos sostienen que el mayor número de actos de corrupción surgieron en el ámbito de la contratación pública, concretamente en el entorno local, y mayoritariamente en relación con el urbanismo, surgidos al calor de la burbuja inmobiliaria.

2. En los últimos años se han creado una batería de nuevos instrumentos de distinto alcance en el ámbito del Derecho administrativo para combatir la corrupción en España. Es innegable la gravedad de este tipo de conductas, lo que ha llevado al legislador a tomar nota para hacerles frente. Está en marcha un Anteproyecto de LCSP que actualiza la vigente norma sobre contratación pública y pretende asegurar el cumplimiento de los objetivos públicos.

3. La normativa europea lleva incorporando y fortaleciendo mecanismos contra la corrupción en las sucesivas generaciones de directivas sobre contratación pública. La cuarta generación incluye reglas para garantizar los principios clásicos de contratación, no solo en la fase de adjudicación, sino también en las de ejecución. El principio de integridad ha cobrado un papel relevante en la Directiva 2014/24 y su norma de trasposición, el Anteproyecto LCSP, como elemento clave para actualizar los mecanismos para combatir la corrupción en los procedimientos de contratación.

4. Hay cierto consenso para afirmar que un aumento en la transparencia y publicidad de la actividad de la administración dificulta la perpetración de actos de corrupción. Han sido muy importantes en este aspecto la aprobación de la LTAIBG y del Estatuto del alto cargo, que articulan mecanismos jurídicos para actuar contra las personas que llevan a cabo prácticas corruptas. Se ha reconocido el derecho de acceso a la información pública por parte de los administrados, se ha obligado a difundir por parte de la administración numerosa información y se han endurecido las incompatibilidades y limitaciones de los altos cargos con el fin de evitar que surjan conflictos de intereses.

5. La buena gestión de los fondos públicos en materia de contratación pasa por una buena capacitación del órgano que constituye la Mesa de contratación. Se han 
incluido en la LTAIBG una serie de principios de buen gobierno, como la imparcialidad o la independencia a la hora de tomar las decisiones, siendo esencial que la presencia de perfiles técnicos en dicho órgano sea predominante.

6. Otra vía de corrupción en la contratación pública supone la modificación de un contrato una vez adjudicado, puesto que además de desvirtuar el proceso de selección, podría introducir compensaciones a una oferta realizada en el contexto de redes clientelares. La facultad de ius variandi por parte de la administración ha ido progresivamente restringiéndose, tanto jurisprudencial como normativamente. Se han estableciendo supuestos tasados por los que la misma pueda ser de aplicación, así como la necesaria publicidad cuando se produzca.

7. Un problema, en principio ajeno a la administración, es la posibilidad de los operadores económicos de establecer pactos colusorios para falsear las licitaciones. Sin embargo, reforzando las herramientas de diferentes organismos, como la CNMC, y estableciendo modelos de conducta en los pliegos, por ejemplo, cabría un mayor control sobre la posibilidad de que se filtren ofertas distorsionadas. La generalización de la división del contrato en lotes que incluye la Directiva 2014/24/UE posibilita la entrada de más PYME en el proceso de licitación, lo que supone un aumento de competidores.

8. La rendición de cuentas de la actividad administrativa es un elemento esencial a la hora de cumplir con los requisitos de transparencia. Para ello se han creado una serie de instrumentos, como la Plataforma de contratación del sector público o el Consejo de transparencia, con el fin de hacer pública un conjunto de información sobre las medidas adoptadas en el ámbito de la contratación pública.

9. La permanencia de bienes defraudados en el patrimonio de los corruptos genera una sensación de impunidad frente a un acto de corrupción. En ese sentido, cobra especial relevancia la creación de la ORGA, puesto que permite reincorporar al erario público los bienes defraudados mediante el sistema del decomiso autónomo. Ello infunde confianza en el sistema institucional y supone un elemento disuasorio más a la hora de cometer actos de corrupción.

10. Finalmente, existen un conjunto de organismos de control de la actividad de la administración que, en mayor o menor medida, detectan prácticas corruptas, tanto en la contratación como en otros ámbitos. Destacan la Oficina de conflictos de intereses y el Consejo de la Transparencia, ambos de reciente creación, como supervisores del cumplimiento de la legalidad. 


\section{FUENTES CONSULTADAS}

\subsection{Doctrina}

6.1.1. Obras monográficas

- Aymerich CAno, C. Un problema pendiente: la anulación de los contratos administrativos afectados por actos de corrupción. Thomson Reuters, Cizur Menor (Navarra), 2015.

- Cerrillo i Martínez, A. El Principio de Integridad en la Contratación Pública. Thomson Reuters, Cizur Menor (Navarra), 2014.

- Razquin Lizarraga, M. M. Contratos públicos y Derecho comunitario. Aranzadi, Pamplona, 1996.

- SAJó, A. Political Corruption in Transaction. CEU Press, Budapest - New York, 2002.

- Santamaría Pastor, J. A. Principios de Derecho Administrativo General. Volumen II. Iustel, Madrid, 2015.

- VÁzQuez Matilla, F. J. La modificación de los contratos públicos. Thomson Reuters, Cizur Menor (Navarra), 2015.

\subsubsection{Artículos doctrinales}

- BATET JiMÉNEZ, P. “Reflexiones sobre el fraccionamiento indebido de los contratos” en Observatorio de Contratación Pública, 2015. Recuperado el 12 de octubre de 2015 en: http://www.obcp.es/index.php/mod.opiniones/mem.detalle/id.204/chk.63802615ec54b48ac7 $\underline{6 c 0 a 34 \mathrm{e} 3 \mathrm{ed} 8804}$

- Bernal Blay, M. A. "El principio de objetividad en la contratación pública", en Documentación Administrativa, núm. 289, 2011, págs. 129 - 150.

- Blanco LóPez, F. “Transparencia y motivación de la adjudicación” en Observatorio de Contratación Pública, 2015. Recuperado el 4 de octubre de 2015 en:

http://www.obcp.es/index.php/mod.opiniones/mem.detalle/id.186/relcategoria.208/relmenu. 3/chk.3f45a8d43fbafae856ccde1e47f06a3d

- Bustos Gisbert, R. “Corrupción política: un análisis desde la teoría y la realidad constitucional” en Teoría y realidad constitucional, núm. 25, 2010, págs. 69 - 108.

- Cano Larrotcha, J. "La inminente adaptación de la Ley de Contratos del Sector Público a las nuevas Directivas comunitarias", en Abogados y Consultores de Administración Local, 2015. Recuperado el 1 de octubre de 2015 en:

http://www.acalsl.com/blog/2015/03/la-inminente-adapacion-de-la-ley-de-contratos-del- 
sector-publico-a-las-nuevas-directivas-comunitarias

- Cantera Cuartango, J. M. "La Mesa de Contratación: un instrumento de control financiero, del gasto público y de legalidad en tiempos de crisis económica" en Auditoría Pública, núm. 58, 2012, págs. 51 - 60.

- Cerrillo I Martínez, A. “Transparencia administrativa y lucha contra la corrupción en la Administración local” en Anuario del Gobierno Local de la Fundación Democracia y Gobierno Local, 2011, págs. 277 - 313.

- De la Morena LóPez, J. "Evolución histórica de la contratación pública en España", en Observatorio de Contratación Pública, 2012. Recuperado el 1 de octubre de 2015 en: http://www.obcp.es/index.php/mod.opiniones/mem.detalle/id.57/relcategoria.121/relmenu.3/ chk.e2db6ab74524409a96997ab947dc3075

- Fernández NaVAJAS, E. "La contratación pública en el ordenamiento comunitario", en Revista jurídica de Navarra, núm. 9, 1990, págs. 195 - 208.

- Gallego CóRCOLES, I. "La modificación de los contratos en la cuarta generación de directivas sobre contratación pública" en Congreso AEPDA, 2014.

- Gimeno Feliu, J. M. "Los efectos jurídicos de las directivas de contratación pública ante el vencimiento del plazo de transposición sin nueva ley de contratos públicos" en Observatorio de Contratación Pública, 2015. Recuperado el 6 de octubre de 2015: http://www.obcp.es/index.php/mod.documentos/mem.descargar/fichero.documentos 7\%232E $\% 231 \mathrm{~J} \% 232 \mathrm{E} \% 23 \mathrm{M}$ Gimeno\%232E\%23 pdf 4b46c93e\%232E $\% 23$ pdf/chk.06139d94938569f1561537cef873c101

- Gimeno Feliu, J. M. "La reforma comunitaria en materia de contratos públicos y su incidencia en la legislación española. Una visión desde la perspectiva de la integridad" en Congreso AEPDA, 2015. Recuperado el 5 de octubre de 2015 en: http://www.csital.org/sites/default/files/Pon\%C3\%A8ncia\%20Jos\%C3\%A9\%20Mar \%C3\%ADa\%20Gimeno.pdf

- Gimeno Feliu, J. M. "Reforma de la normativa europea sobre contratación administrativa y transparencia en la contratación por parte del sector público" en Seminario sobre Transparencia administrativa y protección de los intereses financieros de la Unión Europea en la Eurorregión Galicia-Norte de Portugal, 2014. Recuperado el 15 de octubre de 2015 en: http://egap.xunta.es/recursos/pdf/[1 1399371138]03.pdf

- Gimeno Feliu, J. M. "La obligación de publicidad de todas las licitaciones en la plataforma de contratos del sector público" en Observatorio de Contratación Pública, 2014. Recuperado el 2 de octubre de 2015 en: 
http://www.obcp.es/index.php/mod.opiniones/mem.detalle/id.153/relcategoria.121/relmenu. 3/chk.577429fa7149b11b2d930ebe5b579d9f

- Gimeno Feliu, J. M. "Decálogo de reglas para prevenir la corrupción en los contratos públicos" en Observatorio de Contratación Pública, 2014. Recuperado el 15 de septiembre de 2015 en:

http://www.obcp.es/index.php/mod.opiniones/mem.detalle/id.180/relcategoria.208/relmenu. 3/chk.1b2c9f6d99eecf44223c17ac60720747

- JaÉn VAlLejo, M. "Recuperación de activos derivados del delito: un objetivo prioritario de la reforma penal” en Diario La Ley, núm. 8545, 2015.

- Kaufmann, D. "Diez mitos sobre la gobernabilidad y la corrupción" en Finanzas \& Desarrollo, 2005, págs. 41 a 43. Recuperado el 15 de octubre de 2015 en:

https://www.imf.org/external/pubs/ft/fandd/spa/2005/09/pdf/basics.pdf

- LÓPEZ MiÑo, A. "Insuficiencia del derecho español para impedir y corregir la colusión en la contratación pública" en Proyecto de investigación "Contratación pública y transparencia: alcance y límites de los principios de publicidad y libre competencia”, 2012.

- Malem SeÑA, J. F. "La corrupción política” en Jueces para la democracia, núm. 37, 2000, págs. $26-34$.

- Martínez Fernández, J. M. "La urgencia en la la transposición de las directivas de contratación ante la errática política en Contratación Pública" en Observatorio de Contratación Pública, 2014. Recuperado el 25 de septiembre de 2015 en:

http://www.obcp.es/index.php/mod.opiniones/mem.detalle/id.147/relcategoria.208/relmenu. 3/chk.1bb267c7d9cb09535137ea30840a2e13

- Morell OcaÑA, L. "La objetividad de la Administración Pública y otros componentes de la ética de la institución" en Revista Española de Derecho Administrativo, núm. 111, 2001, págs. $347-372$.

- Moreno Molina, J. A. "El anteproyecto de nueva ley de contratos del sector público y su imprescindible aprobación" en Observatorio de Contratación Pública, 2014. Recuperado el 26 de septiembre de 2015 en:

http://www.obcp.es/index.php/mod.opiniones/mem.detalle/id.147/relcategoria.208/relmenu. $\underline{\text { 3/chk.1bb267c7d9cb09535137ea30840a2e13 }}$

- RazQuin Lizarraga, M. M. "Llega la transparencia” en Observatorio de Contratación Pública, 2015. Recuperado el 18 de noviembre de 2015 en:

http://www.obcp.es/index.php/mod.opiniones/mem.detalle/id.216/relcategoria.121/relmenu. 


\section{3/chk.432d81119283a4d5d1b8f36f34844888}

- Rivero Ortega, R. "Derecho administrativo, reformas de segunda generación, desarrollo y control de la corrupción" en XVIII Concurso de Ensayos del CLAD sobre Reforma del Estado y Modernización de la Administración Pública, 2014. Recuperado el 24 de octubre de 2015 en: http://siare.clad.org/fulltext/0052007.pdf

- SÁnchez Graells, A. “El 'nuevo’ principio de competencia en la Directiva 2014/24: ¿un nuevo juego de presunciones?” en Observatorio de Contratación Pública, 2014. Recuperado el 2 de octubre de 2015 en:

http://www.obcp.es/index.php/mod.opiniones/mem.detalle/id.157/relcategoria.121/relmenu. 3/chk.2deb0e818e9d4231ea49db81b85bf449

- Sanmartín Mora, M. A. "El Registro de Contratos del Sector Público como herramienta para el cumplimiento de las obligaciones de transparencia" en Observatorio de Contratación Pública, 2015. Recuperado el 14 de noviembre de 2015 en:

http://www.obcp.es/index.php/mod.opiniones/mem.detalle/id.200/relcategoria.208/relmenu. $\underline{3 / \text { chk.e3e4b60f68edba6e80ff8130537705e7 }}$

- VÁzquez MatiLla, J. F. "La corrupción una barrera a la eficiencia e integridad en la compra pública" en Observatorio de Contratación Pública, 2012. Recuperado el 3 de noviembre de 2015 en:

http://www.obcp.es/index.php/mod.opiniones/mem.detalle/id.80/relcategoria.121/relmenu.3/ chk.197449cc92600ed0a6d22b3a98431ebd

- Villoria Mendieta, M. y JimÉnez SÁnchez, F. "La corrupción en España (20042010): datos, percepción y efectos" en Revista española de investigaciones sociológicas, núm. 138, 2012, págs. 109 - 134.

\subsection{Informes oficiales y estudios institucionales}

- Abogacía del Estado. Informe 3/2015, de 27 de enero de 2015.

- CIS. "Indicadores. Principales problemas que tiene España", 2015. Recuperado el 4 de diciembre de 2015 en:

http://www.cis.es/opencms/-Archivos/Indicadores/documentos html/TresProblemas.html

- Cis. "Barómetro de junio". Estudio núm. 2905, 2011. Recuperado el 1 de octubre de 2015 en:

http://www.cis.es/cis/export/sites/default/-Archivos/Marginales/2900_2919/2905/Es2905.pdf

- CNMC. "Análisis de la contratación pública en España: oportunidades de mejora desde 
el punto de vista de la competencia", 2015. Recuperado el 1 de octubre de 2015 en: http://www.cnmc.es/Portals/0/Notas\%20de

\%20prensa/201502 Informe ContratacionPublica.pdf

- Comisión Europea. "Public Procurement Indicators 2013”, 2015. Recuperado el 10 de octubre de 2015 en:

http://ec.europa.eu/DocsRoom/documents/11022/attachments/1/translations/en/renditions/native

- COMISIÓN EUROPEA. "Informe sobre la lucha contra la corrupción”, 2014. Recuperado el 8 de octubre de 2015 en: http://europa.eu/rapid/press-release IP-14-86 es.htm

- Junta Consultiva de Contratación del Estado. Informe 69/2008, de 31 de marzo de 2009.

- Ministerio de Hacienda. "Informe y conclusiones de la comisión de expertos para el estudio y diagnóstico de la situación de la contratación pública”, 2014. Recuperado el 2 de noviembre de 2015 en:

http://www.minhap.gob.es/Documentacion/Publico/Subsecretaria/Gabinete

\%20Tecnico/libro\%20contratacion.pdf

- OCDE. "Public Procurement for Sustainable and Inclusive Growth". París, 2012.

Recuperado el 10 de octubre de 2015 en:

http://www.oecd.org/gov/ethics/PublicProcurementRev9.pdf

- OCDE. "Principles for Integrity in Public procurement". París, 2009. Recuperado el 1 de octubre de 2015 en: http://www.oecd.org/gov/ethics/48994520.pdf

- Portal De la Transparencia. "Contratos, convenios y subvenciones", 2015. Recuperado el 25 de octubre de 2015 en:

http://transparencia.gob.es/transparencia/transparencia Home/index/categorias/Contratosconvenios-subvenciones/Contratos.html\#

- Transparencia Internacional. "Barómetro Global de la Corrupción", 2013. Recuperado el 12 de octubre de 2015 en: http://transparencia.org.es/bgc-2013/

\subsection{Normativa}

- Constitución Española, de 6 de diciembre de 1978.

- Directivas 2014/24/UE, sobre contratación pública, y 2014/23/UE, relativa a la adjudicación de contratos y de concesión, del Parlamento Europeo y del Consejo, de 26 de febrero de 2014.

- Ley 3/2015, de 30 de marzo, reguladora del ejercicio del Alto Cargo de la 
Administración General del Estado.

- Ley 19/2013, de 9 de diciembre, de Transparencia, Acceso a la Información pública y Buen Gobierno.

- Ley 15/2007, de 3 de julio, de Defensa de la Competencia.

- Ley 11/2007, de 22 de junio, de Acceso Electrónico de los Ciudadanos a los Servicios Públicos

- Ley 7/2007, de 12 de abril, del Estatuto Básico del Empleado Público.

- Ley 30/1992, de 26 de noviembre, de Régimen Jurídico de las Administraciones Públicas y del Procedimiento Administrativo Común.

- Ley Orgánica 2/1982, de 12 de mayo, del Tribunal de Cuentas.

- Real Decreto 948/2015, de 23 de octubre, por el que se regula la Oficina de Recuperación y Gestión de Activos

- Real Decreto 799/2005, de 1 de julio, por el que se regulan las inspecciones generales de servicios de los departamentos ministeriales.

- Real Decreto de 14 de septiembre de 1882 por el que se aprueba la Ley de Enjuiciamiento Criminal.

- Real Decreto Legislativo 3/2011, de 14 de noviembre, por el que se aprueba el texto refundido de la Ley de Contratos del Sector Público.

\subsection{Resoluciones judiciales}

- STJUE de 16 de septiembre de 2013, caso España contra Comisión Europea (TJCE 2013\282).

- STJUE de 4 de julio de 2006, asunto Adeneler (TJCE 2006\181).

- STJUE de 29 de abril de 2004, asunto Succhi di Frutta (TJCE 2004\125).

- STJUE de 17 de septiembre de 2002, asunto Concordia Bus Finlad (TJCE\2002\251).

- STJUE de 8 de octubre de 1987, asunto Kolpinghuis Nijmegen.

- STPICE de 12 de marzo de 2008, asunto Evropaïki Dynamiki (TJCEL2008\50).

- STS (Sala de lo Contencioso Administrativo, Sección7a) de 10 de octubre de 2012 (RJ 201219809).

- STS (Sala de lo Contencioso Administrativo, Sección7a) de 17 julio 2012 (RJ 2012\7912). 